\title{
A review of microwave testing of glass fibre-reinforced polymer composites
}

DOI:

10.1080/10589759.2019.1605603

\section{Document Version}

Accepted author manuscript

Link to publication record in Manchester Research Explorer

\section{Citation for published version (APA):}

Li, Z., Haigh, A., Soutis, C., Gibson, A., \& Wang, P. (2019). A review of microwave testing of glass fibre-reinforced polymer composites. Nondestructive testing and evaluation. https://doi.org/10.1080/10589759.2019.1605603

\section{Published in:}

Nondestructive testing and evaluation

\section{Citing this paper}

Please note that where the full-text provided on Manchester Research Explorer is the Author Accepted Manuscript or Proof version this may differ from the final Published version. If citing, it is advised that you check and use the publisher's definitive version.

\section{General rights}

Copyright and moral rights for the publications made accessible in the Research Explorer are retained by the authors and/or other copyright owners and it is a condition of accessing publications that users recognise and abide by the legal requirements associated with these rights.

\section{Takedown policy}

If you believe that this document breaches copyright please refer to the University of Manchester's Takedown Procedures [http://man.ac.uk/04Y6Bo] or contact uml.scholarlycommunications@manchester.ac.uk providing relevant details, so we can investigate your claim.

\section{OPEN ACCESS}




\section{Manuscript Details}

\section{Manuscript number}

Title

Article type
NDTEINT_2018_523

A review of microwave testing of glass fibre-reinforced polymer composites

Research Paper

\section{Abstract}

Microwave non-destructive testing has received extensive attention in recent years owing to its advantages of noncontact inspection, no need for a coupling medium or sensors attached on the object surface, a relatively easy measurement setup and no ionising radiation hazards. As an alternative method of traditional X-ray and ultrasonic testing methods, it has been used for evaluation of glass fibre-reinforced polymer composite structures. This paper provides a comprehensive overview of the microwave-based techniques for composites, including material characterisation, cure state monitoring, strain sensing, thickness measurement, near-field and far-field damage detection. Discussions on the research trends are presented.

\section{Keywords}

Corresponding Author

Corresponding Author's Institution

Order of Authors

Suggested reviewers microwave testing; glass fibre; composites; electric permittivity; non-destructive evaluation.

\section{Constantinos Soutis}

The University of Manchester, Manchester

Zhen Li, Arthur Haigh, Constantinos Soutis, Andrew Gibson, Ping WANG

Gui Yun Tian, Jochen Moll, Yongmao Pei, Adrian Porch 


\section{Submission Files Included in this PDF}

\section{File Name [File Type]}

Covering_letter_ndte_2018.doc [Cover Letter]

highlights_ndte_2018.doc [Highlights]

mw_gfrp_v8.doc [Manuscript File]

fig1.tif [Figure]

fig2a.tif [Figure]

fig2b.tif [Figure]

fig3a.tif [Figure]

fig3b.tif [Figure]

fig3c.tif [Figure]

fig3d.tif [Figure]

fig4.tif [Figure]

fig5.tif [Figure]

fig6.tif [Figure]

fig7a.tif [Figure]

fig7b.tif [Figure]

fig8.tif [Figure]

fig9a.jpg [Figure]

fig9b.jpg [Figure]

fig9c.jpg [Figure]

fig10a.tif [Figure]

fig10b.JPG [Figure]

fig10c.tif [Figure]

fig10d.tif [Figure]

fig10e.tif [Figure]

fig11.jpg [Figure]

fig12a.tif [Figure]

fig12b.tif [Figure]

fig13a.jpg [Figure]

fig13b.jpg [Figure]

fig14.jpg [Figure]

fig15.tif [Figure]

To view all the submission files, including those not included in the PDF, click on the manuscript title on your EVISE Homepage, then click 'Download zip file'. 


\section{Covering letter for submission of a paper to $N D T \& E$ International}

3 October 2018

The Editor:

NDT \& E International

Iowa State University, Ames, Iowa, USA

Dear Prof. D. E. Chimenti,

We wish to submit a new manuscript entitled "A review of microwave testing of glass fibrereinforced polymer composites" for your consideration.

We confirm that this work is original and has not been published elsewhere nor is it currently under consideration for publication elsewhere.

In this paper, we provide a comprehensive overview of the principles of microwave testing and its applications for glass fibre-reinforced polymer composites, including material characterisation, strain sensing, near-field and far-field damage detection. The microwave non-destructive testing methods have received extensive attention in recent years owing to its advantages of non-contact inspection, no need for a coupling medium or sensors attached on the object surface, an easy measurement setup and no ionising radiation hazards. The review presented here can contribute to guidance for future research work on microwave-related electromagnetic analysis and non-destructive evaluation.

The paper should be of interest to readers in the area of study of microwave non-destructive testing.

Thank you for your consideration of this manuscript.

Sincerely,

Constantinos Soutis

Aerospace Research Institute, The University of Manchester

James Lighthill Building, Sackville Street, Manchester M13 9PL, UK

Email: constantinos.soutis@manchester.ac.uk 


\section{Highlights}

- An overview of the microwave-based techniques for glass fibre composites is given.

- Based on the detection principles, the methods are classified into five categories.

- The electromagnetic properties of glass fibre composites are thoroughly discussed. 
A review of microwave testing of glass fibre-reinforced polymer composites Zhen $\mathrm{Li}^{1,2}$, Arthur Haigh ${ }^{3}$, Constantinos Soutis ${ }^{2 *}$, Andrew Gibson ${ }^{4}$ and Ping Wang ${ }^{1}$

${ }^{1}$ College of Automation Engineering, Nanjing University of Aeronautics and Astronautics, Nanjing, 211106, China

${ }^{2}$ Aerospace Research Institute, The University of Manchester, Manchester, M13 9PL, UK

${ }^{3}$ School of Electrical and Electronic Engineering, The University of Manchester, Manchester, M13 9PL, UK

${ }^{4}$ Faculty of Science and Engineering, Manchester Metropolitan University, Manchester, M1 5GD, UK

*Corresponding author: constantinos.soutis@manchester.ac.uk

\begin{abstract}
Microwave non-destructive testing has received extensive attention in recent years owing to its advantages of non-contact inspection, no need for a coupling medium or sensors attached on the object surface, a relatively easy measurement setup and no ionising radiation hazards. As an alternative method of traditional X-ray and ultrasonic testing methods, it has been used for evaluation of glass fibre-reinforced polymer composite structures. This paper provides a comprehensive overview of the microwavebased techniques for composites, including material characterisation, cure state monitoring, strain sensing, thickness measurement, near-field and far-field damage detection. Discussions on the research trends are presented.
\end{abstract}

Keywords: microwave testing, glass fibre, composites, electric permittivity, nondestructive evaluation. 


\section{Introduction}

Glass fibre has comparable tensile and compressive strengths to carbon fibre. Although the stiffness is not as high as that of carbon fibre, it is much cheaper and less brittle (higher strain to failure) when used in polymer composites. Due to the lightweight and economical characteristics, glass fibre-reinforced polymer (GFRP) composites have been widely used in aerospace, naval, automotive, construction and wind energy industries [1]. It is noted that air voids could occur during the manufacturing process, and in service GFRP composites are subjected to varied hazards, such as degradation caused by cyclic loads, lightning, hail or ice impact. The typical damage includes fibre/matrix debonding, matrix cracking, delamination (ply separation) and ultimately fibre breakage. Much of these damage modes happen internally and are hardly visible, as GFRP composites are almost opaque for wavelengths in the visible regime. Hence, most optical methods (e.g., visual inspection) are only capable of detecting faults at the surface or flaws expanding to the surface. Considerable efforts have been devoted to utilising non-destructive testing (NDT) for accurate evaluation of the structural integrity. A number of NDT techniques are available for selection, such as conventional strain gauges, ultrasonic testing, guided Lamb waves [2,3], acoustic emission [4], infrared thermography, optical fibre sensing, shearography, eddy current testing (ECT) [5], terahertz imaging [6] and X-ray tomography [7]. However, each NDT method has its own specific advantages, disadvantages and the applications to which it is particularly suited. The NDT research community is therefore continuously searching for new solutions.

An alternative method is the microwave-based. Microwaves are electromagnetic (EM) radiation with frequencies between $300 \mathrm{MHz}$ (wavelength of $1 \mathrm{~m}$ ) and $300 \mathrm{GHz}$ 
(wavelength of $1 \mathrm{~mm}$ ). They are best known for the use in telecommunications and manufacturing (e.g., food processing and composite curing [8,9]), while they can also be used for material characterisation, estimation of mechanical properties [10], strain sensing [11,12] and damage evaluation [13-15]. Measuring the electromagnetic properties (i.e., permittivity and permeability) can be helpful for assessment of the quality of the material (e.g., moisture content [16], porosity [17] and fibre volume fraction [18]), dimensional metrology (thickness measurement), cure state monitoring, optimal design of the experimental setups and quantitative analysis of the detection results. In damage detection, the amplitude and phase of the received signals can be affected by the variations of the thickness or electromagnetic properties at the damaged region. When employed for glass fibre composites, microwave techniques have proven to be superior to some other NDT methods [19]. There are several attributes when applying microwave testing, such as non-contact inspection, no need for transducers bonded on the surface or coupling agent to couple the microwaves into the test object, no need for complicated signal post-processing, operator friendly, relatively inexpensive, one-sided scanning, good repeatability and non-ionising (unlike X-ray and gamma radiation). Except for heating purposes, the signal power used is generally low, a few milliwatts, hence there is no safety concern or need for protection.

In the past the complicated and expensive microwave equipment hindered the widespread application of the microwave methods, but this situation is changing now due to the increasing availability of low-cost high integrated microwave components [20]. In recognition of the growing interest in microwave testing, in 2011 the Expert committee for microwave and THz testing procedures of the German Society of NonDestructive Testing (DGZfP) was founded. And in 2014 the Microwave Testing 
Committee was established by the American Society for Non-destructive Testing (ASNT). Microwave testing was furthermore recognised as its own NDT method in the 2016 edition of the ASNT standards, and the certifications for Level I and Level II microwave testing inspectors are currently under development [21].

In this paper the electromagnetic properties (or dielectric properties) of glass fibre polymer composites and definitions of the near-field and far-field inspection approaches that are closely related to the microwave testing are addressed first. Then the methods for material characterisation are introduced. Based on the detection principles, the microwave testing methods for GFRP composites are classified into five categories: near-field detection with an open-ended probe, near-field resonance methods, far-field sensing methods, focusing methods and microwave-based thermography (integration with another NDT method). The basic principles, experimental setup, capabilities and limitations of each technique are reviewed in detail.

\section{Concepts involved in microwave testing for glass fibre composites}

\subsection{Electromagnetic properties of glass fibre composites}

The electric permittivity $\varepsilon$ and magnetic permeability $\mu$ are the two main parameters of EM properties, which describe the interaction between the material and the EM field. As both glass fibre and epoxy are non-magnetic, permittivity is the parameter of interest in the present work. The permittivity $\varepsilon$ can be written as [22]

$$
\varepsilon=\varepsilon_{0} \varepsilon_{r}=\varepsilon_{0}\left(\varepsilon_{r}^{\prime}-j \varepsilon_{r}^{\prime \prime}\right)=\varepsilon_{0} \varepsilon_{r}^{\prime}(1-j \tan \delta)
$$

where $\varepsilon_{0}$ is the permittivity of free space (i.e., $8.8542 \times 10^{-12} \mathrm{~F} \cdot \mathrm{m}^{-1}$ ), and $\varepsilon_{r}$ is the relative permittivity. The real part $\varepsilon_{r}^{\prime}$, or dielectric constant, is related to the ability of a material to store the electric field energy, while $\varepsilon_{r}^{\prime \prime}$ accounts for the dissipation of the 
energy within the material in the form of heat. The loss tangent $\tan \delta\left(=\varepsilon_{r}^{\prime \prime} / \varepsilon_{r}^{\prime}\right)$ can also be used to quantify the dielectric loss. $\varepsilon_{r}^{\prime \prime}$ is positive due to energy conservation. The complex permittivity is a function of frequency and temperature.

For each component, both glass fibres and epoxy resin are nonconductive, and the dielectric properties of some typical fibres and resins are listed in Table 1 and Table 2. For the glass fibre-epoxy mixture, its effective permittivity change as a function of parameters like frequency, fibre volume fraction, cure state, porosity and fibre orientation. Thus, it is possible to extract useful information about these parameters from the permittivity. Empirical mixing formulae can be adopted for the prediction of the effective dielectric constant, such as Wiener limits, Maxwell Garnett formula and Looyenga formula [29]. In these closed-form solutions, the effective dielectric constant is a function of the dielectric properties of the fibre and resin. The upper and lower bounds of the effective dielectric constant can be provided by Wiener upper limit and Wiener lower limit, respectively [30]. The limits were given based on analysis of laminated structures, which corresponded to fibres orthogonal to or in parallel with the applied electric field. However, most practical cases are between the two limits. More accurate models for description of the anisotropic glass fibre composite structures are needed, as the fibre architecture affects the polarisation in the material. For unidirectional (UD) and multidirectional laminates, Chin et al. [31,32] proposed an equivalent lumped circuit model, where a lamina was built as a parallel lumped resistorcapacitor circuit. This method well predicted the data obtained from free space measurement over X-band (8-12 GHz). In [27], an accurate model for composites with three-dimensional fibre architecture was developed, considering the three-dimensional 
effect of the fibre. It was demonstrated that the prediction result agreed with that provided by the transmission line measurements.

\subsection{Penetration depth of microwaves}

The signal penetration is a practical parameter that should be considered in damage inspection. Due to the lossy medium, the power of the EM signal decays exponentially through the thickness. The penetration depth $d_{p}$ is defined as the depth where the signal magnitude is reduced to $1 / e$ (about $37 \%$ ) in the medium. For a plane wave incident on a half space of a medium, the expression for $d_{p}$ is given by:

$$
d_{p}=\frac{c}{\sqrt{2} \pi f\left\{\varepsilon_{r}^{\prime}\left[\sqrt{1+\left(\frac{\varepsilon_{r}^{\prime \prime}}{\varepsilon_{r}^{\prime}}\right)^{2}}-1\right]\right\}^{1 / 2}}
$$

where $f$ is the operating frequency, and $c$ is the speed of light in free space, 299792458 $\mathrm{m} / \mathrm{s}$.

It is seen that there is an inverse relationship between the signal frequency and the penetration depth. For a GFRP sample with $\varepsilon_{r}^{\prime}=3.49$ and $\tan \delta=0.02$, the penetration depth at $18 \mathrm{GHz}$ is approximately $120 \mathrm{~mm}$ [33]. It is suggested that the high penetration depth offered is sufficient for most of practical inspection applications.

\subsection{Definition of near-field and far-field approaches}

In the cases where the sample is not placed within the probe, in terms of the distance between the microwave probe and the sample under test, microwave testing can be categorised into near-field and far-field approaches. The term "near field" refers to the evanescent field of an open-ended coaxial line or the non-radiative/reactive region of an antenna that exists in the immediate vicinity where mature propagating waves have not yet been formed (Fig. 1). The current distributions on the antenna are affected when an 
object is placed in the reactive region, the boundary of which is commonly given by [34]:

$$
R<0.62 \sqrt{\frac{D^{3}}{\lambda}}
$$

where $D$ is the maximum linear dimension of the antenna (or diameter of a conical antenna), and $\lambda$ is the wavelength in the medium. In the near-field case, the assumption of uniform plane waves is not valid, so Eq. (2) is not suitable for evaluation of the maximum detectable thickness. Here the penetration is associated with the standoff distance (between the inspection surface and the probe/antenna), operating frequency, electromagnetic properties of the materials and boundary conditions.

The far field is the region of operation for most antennae, where the radiation does not change with distance and absorption of the radiation in the far-field region does not feed back to the transmitting antenna. The far-field (Fraunhofer) distance must satisfy three conditions:

$$
R>\frac{2 D^{2}}{\lambda} R \gg D, \lambda
$$

For an antenna, it should be mentioned that there is a radiative near field (Fresnel region) between the reactive near field and the far field. In this region the reactive fields do not dominate. However, unlike the far-field region, the shape of the pattern varies appreciably with distance. Depending on the values of $\mathrm{R}$ and the wavelength, this field may or may not exist. Hence, the radiative near-field region is not in the scope of this paper. To perform a far-field inspection, as shown in Fig. 2, either monostatic configuration (a transmitter and receiver sharing one antenna with a circulator), Fig.2(a), or bistatic configuration (a pair of transmitting and receiving antennae), Fig.2(b), can be used. Each kind has inherent advantages and disadvantages. In the 
monostatic system here, the circulator is a passive non-reciprocal three-port microwave device, which routes microwave signals from the transmitter to the antenna and from the antenna to the receiver and prevents signals from passing directly from the transmitter to receiver. Compared with the bistatic counterpart, the dimensions of the monostatic system are more compact, while the lower isolation can result in a significant leakage [36]. Additional measures must be undertaken to reduce or suppress the undesirable leakage. The bistatic configuration has a high isolation between transmitting and receiving channels. During in-service inspections, commonly only one side of the object under test can be accessed, so the reflection mode is more advantageous.

\section{Microwave characterisation of GFRP composites}

There are mainly two types of permittivity measurement methods: resonant methods and non-resonant methods. Resonant methods can provide permittivity values with high accuracy and sensitivity at the resonance frequencies, while non-resonant methods can characterise materials over a frequency range. In terms of sample preparation, the measurement methods can be categorised as intrusive or non-destructive/non-invasive. Intrusive methods include the resonant method and transmission line method, where cutting and machining of test samples is required. Sample preparation work is labour intensive and cutting sections from the examined component may not be permissible. Open-ended probe method and free space measurement are the two main nondestructive approaches. The permittivity of GFRP can be calculated from one Sparameter (either the transmission coefficient $S_{21}$ or reflection coefficient $S_{11}$ ), which can be measured with the use of a vector network analyser (VNA). 


\subsection{Transmission line method}

Here the sample under test is placed in a measurement cell of a transmission line, which is a short section of a coaxial line or a waveguide as shown in Fig. 3. There are standard test methods that can be referred to: ASTM D7449M-14 [37] (for coaxial line) and ASTM D5568-08 [38] (for waveguide). The Nicolson-Ross method [39] or Tischer model [40] can be employed for the permittivity calculation. The sample need to be cut and perfectly fit within the cell, otherwise the air gaps between the sample and the metallic walls can affect the measurement accuracy [41]. With the gap filled with a lowmelting-point alloy (e.g., silver conductive epoxy), the unwanted effect could be reduced. It is not required to fill the whole measurement cell along the transmission line, i.e., $t_{1} \geq 0$ and $t_{2} \geq 0$. The transmission line technique is useful for broadband frequency measurement of high loss and medium loss materials.

\subsection{Open-ended probe method}

The specimen can be placed in the near-field region (Fig. 4) or in contact with an openended transmission line (e.g., coaxial line [42,43]) or waveguide (e.g., circular waveguide [44] or rectangular waveguide). In the contact measurement, the probe should be pressed against the surface of the sample to reduce the negative effect caused by possible air gaps. As a one-port measurement, the reflection coefficient is used to reveal the information of the permittivity of the material

1) coaxial probe. The electromagnetic fringe field of an open-ended coaxial probe closely surround the tip of the probe [45]. Compared with the waveguides, the coaxial lines can be operated over a relatively wider frequency range. The apertures of the probes for NDT purposes are relatively small, resulting in higher spatial resolutions. In addition, rigid, semi-rigid, semi-flex and flexible coaxial lines are commercially 
available, so hard-to-reach regions of a structure for other NDT methods can be inspected.

There are some off-the-shelf coaxial probes, like Agilent 'Performance' dielectric probe with operating frequencies from $200 \mathrm{MHz}$ to $50 \mathrm{GHz}$. This kind of dielectric probe is well-suited for liquids or semi-solids, as the probe can be immersed in the materials. However, the material under test is assumed "infinite" in size, and the probe is not recommended for accurate estimation of low-loss materials $(\tan \delta<0.5)$ with $\varepsilon_{\mathrm{r}}^{\prime}>5$ [46]. 2) waveguide. The field region around the waveguide is larger than that around the coaxial probe, as the waveguide performs like an antenna. Hence, a higher standoff distance (within the near-field range) is allowed. The rectangular waveguide is commonly operated in the dominant mode, where the electric field inside the waveguide is linearly polarised. Therefore, the open-ended rectangular waveguide is more capable for measurements of anisotropic materials.

Permittivity calculation requires rigorous mathematical formulation of the electromagnetic field outside the probe, while the exact solution of Maxwell's equations is not available. Approximate 2D models of an open-ended probe radiating into the material have been reported [47-50]. However, these models could not be widely applied due to the assumptions made, for example, the problem is considered with an infinite dielectric half-space, the analysis is limited to layered structures, the probe has an infinite waveguide flange and only the dominant mode is studied. Kempin et al. [51] pointed out that using an open-ended waveguide with a standard finite-sized flange could cause errors in evaluating the complex dielectric properties of a composite structure. A novel design of flange with all four edges rounded was proposed to reduce this undesired effect and produce similar electric field distribution at the flange aperture 
to those created by an infinite flange. By recalculating the permittivity of the five layers (three GFRP layers separated by two identical low-density low-permittivity paper honeycomb layers) of a stratified composite structure from the measured data, the improvement in the accuracy of permittivity estimation was demonstrated. Instead of using approximate mathematical models, the finite element method can be employed to provide better description of the experimental arrangements and the electromagnetic field. In [52], as illustrated in Fig.5, a model with the real experimental setup was built, and electromagnetic simulation software and optimisation methods (i.e., quasi-Newton method and particle swarm optimisation (PSO)) were adopted to calculate the permittivity. The permittivity value initially used in the computation was optimised until a converged solution was found, where the simulated reflection coefficients $S_{11}$ approximated the data acquired. From the measurement of a woven glass fibre-reinforced ceramic filled thermoset material, it was indicated that the proposed method can provide more accurate permittivity results.

The open-ended setup is similar to that of the short-circuited line method [53], where the sample is inserted inside the probe and backed by a conductor, as shown in Fig. 6. The short-circuited line method can be viewed as a combination of the transmission line method and the open-ended probe method, but it is a destructive approach and the measurement accuracy is not as good as the transmission line method.

\subsection{Free space measurement}

In the free space method, as shown in Fig. 7, the sample in the form of flat sheet is kept positioned at the reference plane between two identical antennae. A reflection or transmission mode illustrated in Fig. 2 can be employed. Special attention must be paid to the sample geometry and location. The microwave wave front is approximated as a 
plane wave. In the test a high-gain antenna or dielectric lens should be used to meet this requirement. For high-gain (directional) antennae, the sample is placed in the far-field region. For dielectric lenses, the sample is located at the focal point of the lens, and the dimensions need only be on the order of the focal spot size [21]. The lenses can help minimise the diffraction effects due to the edges of the sample that may exist in the former setup [54].

\subsection{Resonant method}

The sample is placed in a resonant cavity (e.g., re-entrant cavities, cylindrical and rectangular cavities) or on an open resonator (e.g., planar microwave resonator, complementary split-ring resonator (CSRR)) [55-57]. The dielectric properties of the sample can be derived from the changes in the resonance frequency and quality factor (or Q factor) of the cavity. The resonance approach is inherently narrowband, and it requires careful sample preparation (spheres or cylinders required) and calibration [58]. More details about this technique can be found in Ref. [59-62].

\subsection{Advantages and limitations}

Each electric permittivity measurement technique has its own advantages and shortcomings. A number of parameters should be taken into account when choosing an appropriate method for GFRP composites:

1) Measuring the permittivity. The electric field in a coaxial line/circular waveguide is not linearly polarised as the rectangular waveguide. Hence, these two methods could not be effective to reveal the anisotropic nature of the fibrereinforced polymer composites.

2) Frequency of interest. For NDT purposes, the permittivity data over a frequency range are more desirable, so the resonant methods are not preferred. 
3) Measurement accuracy. For the transmission line method, uncertainties of $\varepsilon_{r}^{\prime}$ are better than $\pm 1 \%$, and the resolution of $\tan \delta$ is typically \pm 0.01 [63]. For the open-ended probe, the typical uncertainties of $\varepsilon_{r}^{\prime}$ are $\pm 3 \%$. In the free space techniques, the uncertainties for $\varepsilon_{r}^{\prime}$ are in the range of $\pm(1-10) \%$ and those for $\tan \delta$ are from $\pm 5 \%$ to over $20 \%$ [64]. It is seen that destructive methods are more favourable if machining of the sample is acceptable, as high measurement accuracy can be provided.

4) Contact or non-contact measurement. Non-contact method is not affected by sample surface imperfections and no lubricant is required, hence preferable technique.

\section{Microwave non-destructive evaluation methods for GFRP composites}

\subsection{Near-field detection with an open-ended probe}

The open-ended methods for permittivity measurement can also be applied for nondestructive detection. In addition, a horn antenna can be used, while the lateral resolution offered could be less attractive for its larger aperture when compared with the open-ended probes operated over the same frequency range.

The equivalent lumped circuit for this detection method is illustrated in Fig. 8. The capacitance $C_{g}$ is linked to the standoff distance, while the inductance $L_{s}$, capacitance $C_{s}$ and resistance $\mathrm{R}_{\mathrm{s}}$ are associated with the material properties and sample dimensions. Surface unevenness can affect $\mathrm{C}_{\mathrm{g}}$, while damage in the material will lead to changes in $\mathrm{L}_{\mathrm{s}}, \mathrm{C}_{\mathrm{s}}$ and $\mathrm{R}_{\mathrm{s}}$, and subsequently the signal received. Hence, the defect/damage can be identified by evaluating the reflection coefficient $S_{11}$. 
In most of the research work, the signal responses were examined at a predefined frequency. However, it is noted that the responses of the defect/damage at varied frequencies are different. The inspection frequency suitable for one case with a good signal contrast cannot be applied to another case. Hence, selection of the frequency for an optimal signal contrast is mainly made case by case.

\section{(a) open-ended rectangular waveguide}

An open-ended rectangular waveguide is the mostly used probe. Waves can only be transmitted with frequencies above a certain cut-off frequency, which depends on the cross-sectional dimensions. The higher the operating frequency range, the smaller the aperture size. In addition, the spatial resolution of a scan image is highly dependent on the aperture size, not the wavelength [65]. Therefore, there is a compromise between the signal penetration and the spatial resolution.

1) cure state monitoring

Qaddoumi et al. [66] scanned a $25.6 \mathrm{~mm}$ thick conductor-backed fiberglass sample with $18.6 \%$ resin content. In the two-dimensional microwave image at $24 \mathrm{GHz}$ and a standoff distance of $4 \mathrm{~mm}$, a substantial difference in the signal responses between the four inclusion regions (with no resin, uncured resin, $9.4 \%$ resin and $13.8 \%$ resin) was shown. The effect of the standoff distance was also investigated. It was found that it was difficult to distinguish among the inclusions at lower standoff distances (1-3 mm) for the present case. Calibration was needed in order to obtain an estimate of the resin content.

2) Detection of fabrication defects and in-service damage 
Umeda et al. [67] detected air voids and conductive foreign materials in a resin sample. The amplitude and phase of the signal received were presented in a polar coordinate system. The type of the defect can be determined by the direction in which the point was with respect to the reference point of the case with no defect, clockwise for air voids and anticlockwise for conductive materials. The size of the air voids or conductive foreign materials can be estimated by observing the distance between the present point and the referent point.

Qaddoumi et al. [68] presented a theoretical study on detection of disbonds at varied depths in a glass fibre composite sandwich panel. The phase of the reflection coefficient at the waveguide aperture was used as an indicator of damage presence. It was suggested that a combination of frequency and standoff distance could be used for unambiguous depth determination. At $\mathrm{K}$ band (18.0-26.5 GHz) and a standoff distance of $1 \mathrm{~mm}$, all six disbonds were located correctly at three frequencies, i.e., $25.3 \mathrm{GHz}$, 25.5 GHz and 25.7 GHz.

Greenawald et al. [69] detected impact damage and flat bottom holes in $42.5 \mathrm{~mm}$ thick GFRP sandwich composites using three microwave bands: K band, Ka band (26.5-40 $\mathrm{GHz}$ ) and $\mathrm{V}$ band $(50-75 \mathrm{GHz})$. The impact damage was best revealed at $25 \mathrm{GHz}$ with a standoff distance of $0.5 \mathrm{~mm}$, and strongest indications of the presence of the holes were produced at $30 \mathrm{GHz}$ with a standoff distance of $4.0 \mathrm{~mm}$. Optimisation of the inspection parameters was necessary for each specific flaw type and depth.

Green et al. [70] successfully detected the impact damage in a $10 \mathrm{~mm}$ thick composite sample at $35 \mathrm{GHz}$, which is shown in Fig. 9. The area of damage observed visually from the impacted surface (front face) was small compared with that observed on the back 
side. An image generated from microwave inspection over the front face reproduced the size and shape of the overall damage.

Abou-Khousa et al. [71] used Ka-band and V-band waveguides to detect damage in honeycomb composite panels with a thin GFRP laminated skin. In the 2D map of the phase, the embedded flaws were identified and their relative spatial locations and sizes were determined. Some flaws were shown in the V-band images, but not in the Ka-band images. The results given were comparable to those by X-ray imaging (with the exception of flaw depth evaluation).

Hosoi et al. [72] used K-band microwaves to detect slits, fluorine and aluminium films inserted in E-glass fibre composite laminates. The measurement results were found more stable at lower frequencies $(18 \mathrm{GHz})$, while for small defects the measurement sensitivity was better at higher frequencies $(26 \mathrm{GHz})$. It was indicated that microwaves could detect an aluminium film in a at least $30 \mathrm{~mm}$ thick laminate.

Li et al. $[33,73]$ detected delamination in T-joints of wind turbine blades with an $\mathrm{K}$ band waveguide adapter. The waveguide assembly was mounted on an X-Y-Z scanning stage and connected to an HP 8720D VNA by a semi-rigid coaxial cable. A personal computer (PC) was connected to the analyser for data acquisition. From the images produced at $19 \mathrm{GHz}$ and a standoff distance of $5 \mathrm{~mm}$, as shown in Fig. 10 (d-e), it was found that the magnitude was more sensitive to thickness changes (locations of the web and thickness variation), whereas the phase was more useful for delamination detection. In addition, electromagnetic simulation was performed to identify the optimal inspection frequency and standoff distance. It was revealed that the decreased standoff distance could significantly improve the detection sensitivity, and the location of the delamination region could be recognised from the sensitivity curve. When the sample 
was scanned at $19 \mathrm{GHz}$ with a standoff distance of $5 \mathrm{~mm}$, delamination down to $0.2 \mathrm{~mm}$ in width can be detected.

\section{3) Strain sensing}

In an electromagnetic field glass fibre composites behave like uniaxial pseudo-crystals, where the principal axes of anisotropy coincide with the direction of the reinforcement. When mechanical loads are applied, the fibres are mutually displaced, which could lead to changes in the complex permittivity of the composite. Kovalev et al. [74] studied the effect of the mechanical strains and found that there was a linear relationship between the deformation and the dielectric constant. It was also possible to obtain the strain distribution by measuring the dielectric constant with the electric field in different directions with respect to fibre orientation.

\section{(b) open-ended circular waveguide}

Rahman et al. $[75,76]$ detected artificial defects in the fiberglass skin laminate of a sandwich honeycomb structure using a Teflon-filled circular waveguide and an air-filled K-band rectangular waveguide. The inner diameter of the circular waveguide was 6.25 $\mathrm{mm}$, while the inner dimensions of the rectangular waveguide were $10.7 \mathrm{~mm} \times 4.3 \mathrm{~mm}$. The circular and rectangular waveguides were operated in the dominant modes, $\mathrm{TE}_{11}$ and $\mathrm{TE}_{10}$ modes, respectively, where only one propagating mode exists in the frequency band of operation. The standoff distance of the probe was set to $1 \mathrm{~mm}$, and the thickness of the sandwich structure was $13 \mathrm{~mm}$. Both probes were scanned over the surface where the defects were not visible. At $24 \mathrm{GHz}$ the defects were seen in the raster scan images produced by both methods, and the ability of the system to penetrate through the structure was demonstrated.

(c) open-ended coaxial line 
Wang et al. [77] used a coaxial adapter to detect, identify and evaluate the liquid ingress in honeycomb sandwich structures with GFRP skins. This kind of lightweight sandwich structures are susceptible to moisture ingress. The setup of the liquid ingress detection is shown in Fig. 11. In the test, water, ethyl alcohol and oil were intentionally injected into different regions of the honeycomb cores. The top skin was removed for the easy implementation of the fluid injection. The top surface of the core layer was placed in the vicinity of the end of the probe at a distance $(0.5 \mathrm{~mm})$ much smaller than the wavelength. Over 32-40 GHz significant differences in the reflection coefficients corresponding to water, ethyl alcohol and lubricant oil were revealed, and the three liquid types were easily distinguished due to their different polarisation characteristics. A linear relationship between the magnitude of the reflection coefficient and the height of the intruding liquids in the near field of the probe was found. A peak method was proposed to quantify the position and size of the ingress region from a line scan.

\subsection{Near-field resonance methods}

\section{(a) Near-field scanning microwave microscopy (NSMM)}

As shown in Fig. 12, a near-field microwave microscope is generally composed of a resonant cavity and a sharp tip. The sample is placed close to the probing tip, from which evanescent microwaves are emitted. The probe scans across the surface of the object at a fixed standoff distance. The unevenness or material discontinuity of the surface can result in local changes of the parameter values of the air gap and the sample, subsequently the resonance frequency and Q factor of the whole resonant circuit. Thus, a surface contour plot of the resonance frequency can be produced. High resolution can be achieved when using this technique [78]. The sharper the tip is, the higher the spatial 
resolution that would be obtained. However, this is more suited to surface profiling due to the limited penetration of the low-intensity evanescent waves.

\section{(b) Planar resonators}

Microwave planar resonators can be employed for damage detection as well. The electromagnetic field around the resonator can be perturbed due to the presence of defects/damage. Albishi et al. [79] designed a complementary split-ring resonator (CSRR) sensor to detect cracks in a fibreglass material. Two cracks with widths of 150 $\mu \mathrm{m}$ and $200 \mu \mathrm{m}$ and depths of $1.5 \mathrm{~mm}$ were scanned. A maximum frequency shift of more than $312 \mathrm{MHz}$ was observed with respect to the reference case. Mukherjee et al. [80] developed a SRR sensor for imaging of sub-wavelength defects in a GFRP laminate. In the test, three defects, i.e., surface flat bottom holes with a diameter of 0.7 $\mathrm{mm}(\lambda / 45)$, were easily found. Some coupling occurred between two closely-positioned (a distance of $0.7 \mathrm{~mm}$ ) defects and a simple threshold could be applied to enhance the image contrast.

\subsection{Far-field sensing methods}

A pair of antennae are commonly employed for far-field sensing, where the transmission coefficient $\mathrm{S}_{21}$ is analysed in the frequency domain and/or time domain [81]. Moll et al. [82] developed a radar-based sensing system for wind turbine blades with a realistic demonstrator system in the laboratory environment. Two pairs of frequency-modulated continuous-wave (FMCW) bistatic radars, horn antennae operated in the frequency band from 24.05 to $24.25 \mathrm{GHz}$ and 33.4 to $36.0 \mathrm{GHz}$ were employed. The radar sensors were placed at a distance of about $1 \mathrm{~m}$ in front of a wind turbine demonstrator, which consisted of a rotary stage that can rotate the GFRP sample at a maximum frequency of $1 \mathrm{~Hz}$. Two types of damage in the $800 \mathrm{~mm} \times 300 \mathrm{~mm} \times 10 \mathrm{~mm}$ 
GFRP plate were tested: a cut of 30, 60 and $90 \mathrm{~mm}$ in length and a water pack at the backside of the plate. The 24-GHz system was only able to discriminate the difference between the undamaged structure and the water pack, while the $35-\mathrm{GHz}$ radar system successfully identified the structure with cuts and the water pack. In Fig. 13 (b), it is seen that the damage indicator (DI) increases with increasing damage size, which suggests damage quantification potentials of the $35 \mathrm{GHz}$ detection system. In this work, some real environmental conditions, such as variations in temperature or wind speed, were not considered.

Viegas et al. [83] used active $\mathrm{W}$-band $(75-110 \mathrm{GHz})$ radiometry to detect defects (two blind holes of 2 and $4 \mathrm{~mm}$ diameters and $3 \mathrm{~mm}$ depth) in GFRP composites. In the test, an amplified photonic source generating random millimetre-wave noise illuminated the sample. A quasi-optical test bench comprised of polytetrafluoroethylene (PTFE) lenses was used for focusing the free space signal, and the receiver was a high-sensitivity Wband Schottky diode-based radiometer. The 4-mm diameter defect was clearly observed in the transmission signal intensity profile. As the spontaneous thermal radiation of the GFRP sample was lower compared with the transmitted photonic noise, only the changes in the transmission noise due to the air-dielectric interface were detected by the radiometer.

\subsection{Focusing methods}

Focusing techniques can be employed to improve the spatial resolution. For example, a dielectric lens can be used to focus the microwave energy from a high-gain horn antenna to a point. Both high-resolution images and high-signal levels can be obtained when the region of interest is close to the focal point [84], which indicates that this 
approach is limited to detection of damage close the surface of the specimen. The main disadvantage is that most lenses are narrowband since the lens is inherently resonant. As well as the real focusing, the synthetic focusing techniques can be adopted, such as synthetic aperture radar (SAR), microwave holography and digital beam forming. In this kind of methods, mathematical means are employed to synthetically focus the microwave signals to any point in the volume. The synthetic focusing methods can be applied in both near and far fields.

For SAR, a radar antenna is typically mounted on a moving platform, and the phase history of the scattered wavefront recorded varies with the vehicle position over a modest bandwidth obtained through pulsing or chirping the radar frequency [85]. For digital beam forming, radar phased-arrays are operated by creating a beam which can be electronically steered to point in different directions. However, the circuitry for phase shifting is complicated, and the system is currently not cost-effective. In microwave holography, the single-frequency two-dimensional (2D) holography is combined with wideband 2D SAR to produce a three-dimensional (3D) representation of an object [86]. In addition, one can slice the 3D image at various depths (depending on the available signal bandwidth), creating image slices similar to those produced by X-ray computed tomography [87-89]. Inverse synthetic aperture radar (ISAR), analogous to SAR, is not discussed here, for in this method the radar is stationary and the targets are in motion [90]. This setup is not practical in many engineering applications.

\section{(a) Real focusing}

Meier et al. [91] used a focused W-band FMCW radar to detect manufacturing defects (e.g., local regions where there are dry fibres with no resin around) in a GFRP sample. As illustrated in Fig. 14, two offset parabolic mirrors were located to focus the signal on 
the sample (device under test (DUT) shown in Fig.14), and the transmitting and receiving elements were rectangular $15 \mathrm{dBi}$ gain waveguide horn antennae separated by $1 \mathrm{~mm}$ and placed in the focal plane of an offset parabolic mirror. The polarisation of the radar signal was orthogonal to the orientation of the glass fibres. During the measurement the height of the sample was held constant with the focal point of the radar signal in the centre of the $35 \mathrm{~mm}$ thick sample. The Gaussian beam width at the focus point was approximately $15 \mathrm{~mm}$, and the depth resolution was $3.1 \mathrm{~mm}$ inside the sample. In the radar intensity image for $2 \mathrm{~mm}$ deep below surface, the dry fibre fabric was shown due to the difference in the dielectric properties of the glass fibres and the rest of the GFRP component and an increased surface roughness at the dry fibre region.

\section{(b) Synthetic aperture radar}

Nezadal et al. $[92,93]$ employed a W-band SAR system to identify flat bottom holes in GFRP samples. These holes had different diameters $(5,10,15$ and $20 \mathrm{~mm})$ and depths (from 0.5 to $14.5 \mathrm{~mm}$ ), and the overall thickness of the composite plate was $15.0 \mathrm{~mm}$. The magnitude data enabled the detection of holes with residual wall thicknesses up to $7.5 \mathrm{~mm}$. The average of all the magnitudes measured over the frequency range was used in order to reduce unwanted interference patterns and some artefacts generated at a single frequency. By using the phase and time-domain information it was possible to detect all the hidden defects. The test setup had a lateral resolution of approximately 3.0 $\mathrm{mm}$ and a range resolution of approximately $4.3 \mathrm{~mm}$ in free space. The lateral resolution enabled the detection of defects with diameters of down to $5 \mathrm{~mm}$.

\section{(c) Microwave holography}

So far, most of the microwave holography studies were focused on surveillance and concealed weapon detection on personnel $[94,95]$. However, few papers have been 
found on detection of damage in glass fibre composites. Case et al. [88] first applied Sheen's algorithm to detect embedded defects in a $25.4 \mathrm{~mm}$ thick honeycomb composite panel. The top skin was a thin glass fibre composite laminate. Planar disbonds, crushed dielectric core and delaminations (ply separation) were produced at various depths within the thickness. A Q-band (33-50 GHz) open-ended waveguide probe held approximately $22 \mathrm{~mm}$ above the panel. The spatial resolution of the holographic images was high (in the few millimetre range), while the range resolution was around $8.8 \mathrm{~mm}$. The flaws under the skin at a depth of $2 \mathrm{~mm}$ also appeared in the image for the section at a depth of $10 \mathrm{~mm}$. This image distortion along the thickness direction is due to the inadequacy of some assumptions in Sheen's algorithm used, where the amplitude decay with range is not considered, the transmitting and receiving antennae are assumed to be coincident at the midpoint between the two antennae, the speed of the wave travelling through the sample is not delayed, and no refraction exists at the air-sample interface. Future work could be done on the modification of the imaging algorithm.

\subsection{Microwave-based thermography}

The microwave techniques can be combined with other NDT methods for more detailed and better detection performance. For example, microwaves can be used as a heat source (like microwave curing [9]) for thermography. Compared with the existing thermal excitation methods, such as thermal lamps, laser, ultrasonic and pulsed eddy current (PEC), microwaves can provide more uniform, volumetric and selective heating [96-98]. When a microwave signal is applied, the composites will be heated due to the dielectric loss dominated by the polymer matrix [99]. If the penetration depth of the microwave signal is much smaller than the sample thickness, only the material within 
the penetration depth is heated and the rest of the material is heated by thermal conduction. Therefore, the penetration ability of the microwave-based thermography is better than that of conventional microwave NDT techniques.

Damage and defects could be revealed in the thermogram with an infrared (IR) camera. Owing to good performance by commercial infrared cameras, high sensitivity and high spatial resolution (much better than the microwave wavelength) can be offered. In addition, rapid inspection is achievable, as a large area can be inspected within a short time.

When using this specific technique, special attention should be paid to the electromagnetic shielding. According to the guideline issued by the International Commission on Non-Ionizing Radiation Protection (ICNIRP) [100], the reference level for occupational exposure to electromagnetic fields is $50 \mathrm{~W} / \mathrm{m}^{2}$ over $2-300 \mathrm{GHz}$, which is equivalent to an electric field strength of approximately $137 \mathrm{~V} / \mathrm{m}$ in free space. This health and safety requirement should be strictly satisfied in the implementation. In [101], a low power signal (115.2 $\mathrm{mW}$, approximately maximum output of a mobile phone signal) was used with no need for shielding, while the heating time was longer (a few minutes compared with 1-10 $\mathrm{s}$ in the high power case).

A schematic diagram of the microwave thermography approach is illustrated in Fig. 15. A horn antenna is used to direct the waves into the region of interest. A microwave source can be a magnetron, travelling wave tube or signal generator. An IR camera is located on the same side as the excitation source (reflection configuration). The antenna is placed at a distance from the sample that a sufficient field of view for the thermal camera can be provided. This distance affects the microwave illumination pattern (which in turn determines the effective inspection area) and strength at the surface. A 
personal computer is used for setting the measuring instruments, data acquisition and signal post-processing.

In [102], a microwave pulsed thermography system was developed for detection of a hole with a radius of $4.5 \mathrm{~mm}$ in a GFRP sample. A $2.45 \mathrm{GHz}$ magnetron with maximum power $1 \mathrm{~kW}$ was used for microwave excitation. A maximum temperature increase of $0.6{ }^{\circ} \mathrm{C}$ around the hole was observed after $2 \mathrm{~s}$ heating.

\subsection{Discussion on thickness measurement}

An open-ended rectangular waveguide [103-106], a resonant cavity [107] and a planar CSRR [108] can be used for near-field non-contact thickness measurement of thin samples (a few millimetres). For the first method, same as the permittivity calculation, approximate but complicate mathematical models were commonly adopted. In [52], the simulation-assisted open-ended waveguide approach was extended to thickness measurement, and the computation was quicker as only one parameter was involved in this case. For the last two methods, appropriate calibration is needed to establish the relationship between the resonance frequency and the sample thickness. For thick-section composites, either the monostatic or bistatic antenna configuration illustrated in Fig. 2 can be adopted. With known dielectric properties of the material and the time difference obtained between the reflection from the surface and the first reflection from the bottom side, the sample thickness can be determined [109]. UWB antenna can be employed to obtain better time resolution.

\section{Concluding remarks}

The basic principles and types of the microwave testing methods for glass fibrereinforced polymer composites have been presented here. Various applications have been demonstrated: cure state monitoring, thickness measurement, detection of liquid 
ingress, cracks, holes, manufacturing induced defects, absence of adhesive, dry fibre spots (resin starved regions), delamination and impact damage. The advantages and limitations of the five categories of methods have been discussed for the readers' benefit. Though great progress has been made on the development of the microwave detection methods, the potential of microwaves for wider applications is yet to be fully exploited. More work could focus on the following aspects:

(1) Theoretical models: it is demonstrated that some pioneering work on modelling the open-ended waveguide radiating into stratified dielectrics has been done by Zoughi's group at Missouri University of Science and Technology [45]. However, the model developed is limited for specific applications, and more work should be conducted on thorough investigation of the wave propagation in polymer composites. A multi-physics approach is needed when simulating the microwave-based thermography.

(2) Damage classification: as seen above there is a lack of research on differentiating the type of damage, though various types of defects/damage are observed during fabrication or in service (e.g., impact damage). Artificial intelligence (AI) can be introduced for automatic classification. For instance, an artificial neural network (ANN) can be used with input nodes that are matched to the input data format, output nodes in the form of damage probability and intermediate hidden layer nodes. The connection parameters between the nodes can be optimised by training, using a set of tests with and without specific type of defects or in-service induced damage modes.

(3) Microwave planar resonators: several parameters involved in the design of this type of sensors can be adjusted to improve the near-field sensor performance, 
such as type of the feed line (e.g., stripline, microstrip line or coplanar waveguide), type of the resonator (e.g., CSRR or split ring resonator (SRR)), shape of the resonator (e.g., rectangular, polygonal or circular), dimensions of the resonator, damage indicator (e.g., resonance frequency shift or change of the magnitude [110]).

(4) Real-time imaging: In [111], a real-time microwave camera was reported. By using real-time synthetic focusing algorithm and modulated scattering technique (MST), the microwave camera was able to generate high-resolution images of test specimens in real time. Its applicability for damage detection is to be explored.

(5) Use of the RFID technique: the active radio frequency identification (RFID) technology with the capability of damage inspection has started to attract some attention [112]. With a RFID tag attached on the surface of the object under test, the local damage information can be wirelessly interrogated with a RFID reader. Hence, the microwave RFID-based detection concept can be introduced, and further Internet of Things (IoT) can be integrated for remote inspection and long-term structural health monitoring [113].

(6) Automated inspection: there is a high demand for automated inspection by the industry, while many of the applications addressed are still at the laboratory level rather than real service environment. For example, a X-Y or X-Y-Z positioner is often used when scanning a flat specimen, while it does not readily conform to other complex structural configurations (curved surfaces). Future research need be carried out to facilitate industrial adoption. 
Carrigan et al. [114] designed a robotic pipe crawling apparatus to position the open-ended microwave waveguide probe for detection of defects in a highdensity polyethylene (HDPE) pipe. The robotic system consisted of two sets of wheels sprung against the inner wall of the pipe. The rear set was motorised to position the pipe crawler, while the front set was fitted with rotary encoders to measure the linear distance travelled. The microwave probe was held by a rotating clamp head on the front of the robot. A crack with a width of $1 \mathrm{~mm}$ and a depth of $1 \mathrm{~mm}$ in a $9.8 \mathrm{~mm}$ thick pipe was identified in the 2D scan image produced. The scanning speed of the system was not mentioned, while this is also an important feature that should not be ignored, especially when long pipe systems are examined. In [115], a EddyCus ${ }^{\circledR}$ instrument for eddy current testing was presented, and a maximum speed of $300 \mathrm{~mm} / \mathrm{s}$ at a sampling rate of 3000 samples per second was reported.

(7) Potential applications in additive manufacturing (AM): additive manufacturing is an emerging technique where successive layers of material are formed under computer control to create a three-dimensional object. It significantly revolutionises the design of products with complex geometries and concept of spare parts management. However, at present the complex parts are posing difficulties for inspection, and a standard verification procedure for quality control is not established [116]. For this reason, the 3D printing has not been widely used in industry. It is required that any defect should be identified and corrected before finishing parts. For example, porosity of each layer should be checked when fabricating continuous glass fibre reinforced polymer composites $[117,118]$. Microwave testing can be applied for in-process monitoring of 
additive manufacturing. In addition, a customised microwave sensor can be made possible by AM to fit complex (e.g., curved) surfaces.

Hajisaeid et al. [119] first developed an all 3D-printed free space measurement system including focusing lenses, antenna holders, lens holders and sample holder. With respect to redesigning and reprinting flexibility, it was concluded that $3 \mathrm{D}$ printing proved the most practical and feasible choice for rapid prototyping; further research effort is required by academia and industry.

\section{Acknowledgements}

This work was funded by Dean's Doctoral Scholar Award, Faculty of Science and Engineering, The University of Manchester. Special thanks to Professor Robin Sloan (Microwave Inspection Technologies Ltd), Professor Christian Boller (Saarland University, Germany) and Dr Matthieu Gresil for their helpful technical discussions and recommendations.

\section{References}

[1] Soutis C. Fibre reinforced composites in aircraft construction. Prog Aerosp Sci $2005 ; 41: 143-51$

[2] Diamanti K, Hodgkinson JM, Soutis C. Detection of low-velocity impact damage in composite plates using lamb waves. Struct Heal Monit 2004;3:33-41.

[3] Qiu L, Liu B, Yuan S, Su Z, Ren Y. A scanning spatial-wavenumber filter and PZT 2-D cruciform array based on-line damage imaging method of composite structure. Sensors Actuators, A Phys 2016;248:62-72.

[4] Gresil M, Saleh M, Soutis C. Transverse Crack Detection in 3D Angle Interlock Glass Fibre Composites Using Acoustic Emission. Materials (Basel) 2016;9:699. 
[5] Gäbler S, Heuer H, Heinrich G. Measuring and Imaging Permittivity of Insulators Using High-Frequency Eddy-Current Devices. IEEE Trans Instrum Meas 2015;64:2227-38.

[6] Mieloszyk M, Majewska K, Ostachowicz W. THz spectroscopy application for detection and localisation of water inclusion in glass composite. Compos Struct 2018;192:537-44.

[7] Yu B, Blanc R, Soutis C, Withers PJ. Evolution of damage during the fatigue of 3D woven glass-fibre reinforced composites subjected to tension-tension loading observed by time-lapse X-ray tomography. Compos Part A Appl Sci Manuf 2016;82:279-90.

[8] Woo Il Lee, Springer GS. Microwave Curing of Composites. J Compos Mater $1984 ; 18: 387-409$.

[9] Green JE, Nuhiji B, Zivtins K, Bower MP, Grainger R V., Day RJ, et al. Internal Model Control of a Domestic Microwave for Carbon Composite Curing. IEEE Trans Microw Theory Tech 2017;65:4335-46.

[10] Zoughi R, Gray SD, Nowak PS. Microwave nondestructive estimation of cement paste compressive strength. ACI Mater J 1995;92:64-70.

[11] Wilson WC, Moore JP, Juarez PD. Remote strain sensing of CFRP using microwave frequency domain reflectometry. 2016 IEEE Natl. Aerosp. Electron. Conf. Ohio Innov. Summit, Dayton, OH,US: IEEE; 2016, p. 401-6.

[12] Daliri A, Galehdar A, Rowe WST, Ghorbani K, John S. Utilising microstrip patch antenna strain sensors for structural health monitoring. J Intell Mater Syst Struct 2012;23:169-82. 
[13] Kharkovsky S, Zoughi R. Microwave and millimeter wave nondestructive testing and evaluation - Overview and recent advances. IEEE Instrum Meas Mag 2007;10:26-38.

[14] Li Z, Haigh A, Soutis C, Gibson A. Principles and Applications of Microwave Testing for Woven and Non-Woven Carbon Fibre-Reinforced Polymer Composites: a Topical Review. Appl Compos Mater 2018;25:965-82.

[15] Li Z, Haigh A, Soutis C, Gibson A, Sloan R. Applications of microwave techniques for aerospace composites. 2017 IEEE Int. Conf. Microwaves, Antennas, Commun. Electron. Syst., vol. 2017-Novem, Tel Aviv,Israel: IEEE; 2017, p. 1-4.

[16] Haigh AD. A study of microwave moisture measurement in bulk materials. Manchester Metropolitan University, 1994.

[17] Gray S, Ganchev S, Qaddoumi N, Beauregard G, Radford D, Zoughi R. Porosity level estimation in polymer composites using microwaves. Mater Eval $1995 ; 53: 404-8$.

[18] Forssell B. Non-Destructive Measurements of the Glass-Fibre Content in Reinforced Plastics by Means of Microwaves. 4th Eur. Microw. Conf. 1974, IEEE; 1974, p. 132-6.

[19] Gary w. Carriveau. Benchmarking of the State-of-the-Art in Nondestructive Testing/Evaluation for Applicapility in the Composite Armored Vehicle advanced TEchnology demonstrator program. San Antonio: 1993.

[20] Dobmann G, Altpeter I, Sklarczyk C, Pinchuk R. Non-destructive testing with micro-and MM-waves - Where we are - Where we go. Weld World 2012;56:111-20. 
[21] Case JT, Kenderian S. Microwave NDT: An Inspection Method. Mater Eval $2017 ; 75: 339-46$.

[22] D.M.Pozar. Microwave Engineering. vol. 47. Fourth edi. New York: John Wiley \& Sons; 2012.

[23] AGY | Strength in Materials n.d. http://www.agy.com/.

[24] Wilson LK, Salerno JP. Microwave Curing of Epoxy Resins. Nashville,Tennessee, USA: 1978.

[25] Summerscales J. Non-Destructive Testing of Fibre-Reinforced Plastics Composites. 1990 editi. Springer Netherlands; 1990.

[26] Micheli D, Apollo C, Pastore R, Marchetti M. X-Band microwave characterization of carbon-based nanocomposite material, absorption capability comparison and RAS design simulation. Compos Sci Technol 2010;70:400-9.

[27] Li Z, Haigh A, Soutis C, Gibson A, Sloan R. Dielectric constant of a threedimensional woven glass fibre composite: Analysis and measurement. Compos Struct 2017;180:853-61.

[28] Hong W, Xiao P, Li Z, Luo H. Microwave radial dielectric properties of carbon fiber bundle: Modeling, validation and application. Carbon N Y 2014;79:538-43.

[29] Sihvola A. Electromagnetic Mixing Formulas and Applications. The Institution of Engineering and Technology; 1999.

[30] Bal K, Kothari VK. Permittivity of woven fabrics: A comparison of dielectric formulas for air-fiber mixture. IEEE Trans Dielectr Electr Insul 2010;17:881-9.

[31] Chin WS, Lee DG. Binary mixture rule for predicting the dielectric properties of unidirectional E-glass/epoxy composite. Compos Struct 2006;74:153-62. 
[32] Chin WS, Lee DG. Laminating rule for predicting the dielectric properties of Eglass/epoxy laminate composite. Compos Struct 2007;77:373-82.

[33] Li Z, Haigh A, Soutis C, Gibson A, Sloan R. Microwaves Sensor for Wind Turbine Blade Inspection. Appl Compos Mater 2017;24:495-512.

[34] Balanis CA. Antenna Theory: Analysis and Design. 3rd ed. New Jersey: John Wiley \& Sons; 2005.

[35] Djuknic GM. Method of measuring a pattern of electromagnetic radation. US $6,657,596 \mathrm{~B} 2,2002$.

[36] Kapilevich BY, Harmer SW, Bowring NJ. Non-Imaging Microwave and Millimetre-Wave Sensors for Concealed Object Detection. New York: CRC Press; 2014.

[37] ASTM-D7449M-14. Standard Test Method for Measuring Relative Complex Permittivity and Relative Magnetic Permeability of Solid Materials at Microwave Frequencies Using Coaxial Air Line. West Conshohocken, PA, USA: ASTM International; 2014.

[38] ASTM-D5568-08. Standard Test Method for Measuring Relative Complex Permittivity and Relative Magnetic Permeability of Solid Materials at Microwave Frequencies Using Waveguide. West Conshohocken, PA, USA: ASTM International; 2008.

[39] Nicolson AM, Ross GF. Measurement of the Intrinsic Properties Of Materials by Time-Domain Techniques. IEEE Trans Instrum Meas 1970;19:377-82.

[40] Tischer FJ. Measurement of the Wave-Propagation Properties of Plasma in the Microwave Region. IRE Trans Instrum 1960;I-9:167-71. 
[41] Foudazi A, Donnell KM. Effect of sample preparation on microwave material characterization by loaded waveguide technique. IEEE Trans Instrum Meas 2016;65:1669-77.

[42] Bakhtiari S, Ganchev SI, Zoughi R. Analysis of radiation from an open-ended coaxial line into stratified dielectrics. IEEE Trans Microw Theory Tech 1994;42:1261-7.

[43] Ching-Lei Li, Kun-Mu Chen, Li CL, Chen KM. Determination of electromagnetic properties of materials using flanged open-ended coaxial probefull-wave analysis. IEEE Trans Instrum Meas 1995;44:19-27.

[44] Tantot O, Chatard-Moulin M, Guillon P. Measurement of complex permittivity and permeability and thickness of multilayered medium by an open-ended waveguide method. IEEE Trans Instrum Meas 1997;46:519-22.

[45] Zoughi R. Microwave Non-Destructive Testing and Evaluation. vol. 4. Dordrecht: Springer Netherlands; 2000.

[46] Agilent Technologies. Agilent 85070E Dielectric Probe Kit $200 \mathrm{MHz}$ to $50 \mathrm{GHz}$ - Technical Overview. Santa Clara, CA, USA: 2006.

[47] Decreton MC, Gardiol FE. Simple Nondestructive Method for the Measurement of Complex Permittivity. IEEE Trans Instrum Meas 1974;23:434-8.

[48] Bakhtiari S, Ganchev S, Zoughi R. A general formulation for admittance of an open-ended rectangular waveguide radiating into stratified dielectrics. Res Nondestruct Eval 1995;7:75-87.

[49] Stewart JW, Havrilla MJ. Electromagnetic characterization of a magnetic material using an open-ended waveguide probe and a rigorous full-wave multimode model. J Electromagn Waves Appl 2006;20:2037-52. 
[50] Bakhtiari S, Qaddoumi N, Ganchev SI, Zoughi R. Microwave Noncontact Examination of Disbond and Thickness Variation in Stratified Composite Media. IEEE Trans Microw Theory Tech 1994;42:389-95.

[51] Kempin M, Ghasr MT, Case JT, Zoughi R. Modified waveguide flange for evaluation of stratified composites. IEEE Trans Instrum Meas 2014;63:1524-34.

[52] Li Z, Haigh A, Soutis C, Gibson A, Sloan R. A Simulation-Assisted Nondestructive Approach for Permittivity Measurement Using an Open-Ended Microwave Waveguide. J Nondestruct Eval 2018;37:39.

[53] Chao S-H. An uncertainty analysis for the measurement of microwave conductivity and dielectric constant by the short-circuited line method. IEEE Trans Instrum Meas 1986;IM-35:36-41.

[54] Ghodgaonkar DK, Varadan V V., Varadan VK. A Free-Space Method for Measurement of Dielectric Constants and Loss Tangents at Microwave Frequencies. IEEE Trans Instrum Meas 1989;38:789-93.

[55] Kraszewski A. Microwave Aquametry—A Review. J Microw Power 1980;15:209-20.

[56] Lee C Sen, Yang CL. Complementary split-ring resonators for measuring dielectric constants and loss tangents. IEEE Microw Wirel Components Lett $2014 ; 24: 563-5$.

[57] Ansari MAH, Jha AK, Akhter Z, Akhtar MJ. Multi-Band RF Planar Sensor Using Complementary Split Ring Resonator for Testing of Dielectric Materials. IEEE Sens J 2018;18:6596-606.

[58] Kraszewski AW, Nelson SO. Observations on Resonant Cavity Perturbation by Dielectric Objects. IEEE Trans Microw Theory Tech 1992;40:151-5. 
[59] Clarke RN, Rosenberg CB. Fabry-Perot and open resonators at microwave and millimetre wave frequencies, 2-300 GHz. J Phys E 1982;15:9-24.

[60] Danilov I, Heidinger R. New approach for open resonator analysis for dielectric measurements at mm-wavelengths. J Eur Ceram Soc 2003;23:2623-6.

[61] Kaczkowski A, Milewski A. High-Accuracy Wide-Range Measurement Method for Determination of Complex Permittivity in Reentrant Cavity: Part B -Experimental Analysis of Measurement Errors. IEEE Trans Microw Theory Tech $1980 ; 28: 228-31$.

[62] Haigh AD, Thompson F, Gibson AAP, Dillon BM. Analysis and design of a reentrant microwave cavity for the characterisation of single wheat grain kernels. IEE Proc - Sci Meas Technol 2003;150:113-7.

[63] Krupka J. Frequency domain complex permittivity measurements at microwave frequencies. Meas Sci Technol 2006;17:R55-70.

[64] Clarke RN, Gregory AP, Cannell D, Patrick M, Wylie S, Youngs I, et al. A guide to the characterisation of dielectric materials at RF and microwave frequencies. Teddington: 2003.

[65] Li Z. Radio frequency non-destructive evaluation of impact damage in carbon fibre composites. University of Manchester, 2017.

[66] Qaddoumi N, Ganchev S, Zoughi R. Microwave diagnosis of low-density fiberglass composites with resin binder. Res Nondestruct Eval 1996;8:177-88.

[67] Umeda T, Miyashita T, Kako Y. New Evaluation Method of Dielectric Materials Using a Microwave Technique. IEEE Trans Electr Insul 1980;EI-15:340-9.

[68] Qaddoumi N, Zoughi R, Carriveau GW. Microwave detection and depth determination of disbonds in low-permittivity and low-loss thick sandwich 
composites. Res Nondestruct Eval 1996;8:51-63.

[69] Greenawald EC. Microwave NDE of impact damaged fiberglass and elastomer layered composites. AIP Conf. Proc., vol. 509, AIP; 2000, p. 1263-8.

[70] Green G, Campbell P, Zoughi R. An investigation into the potential of microwave NDE for maritime application. 16th World Conf. Non-Destructive Test., Montreal, Canada: 2004, p. 30-7.

[71] Abou-Khousa MA, Ryley A, Kharkovsky S, Zoughi R, Daniels D, Kreitinger N, et al. Comparison of X-Ray, Millimeter Wave, Shearography and ThroughTransmission Ultrasonic Methods for Inspection of Honeycomb Composites. AIP Conf. Proc., vol. 894, AIP; 2007, p. 999-1006.

[72] Hosoi A, Ju Y. Nondestructive detection of defects in GFRP laminates by microwaves. J Solid Mech Mater Eng 2010;4:1711-21.

[73] Li Z, Haigh A, Soutis C, Gibson A, Sloan R, Karimian N. Delamination detection in composite T-joints of wind turbine blades using microwaves. Adv Compos Lett 2016;25:83-6.

[74] Kovalev VP, Baranov GL, Kramar VK. Microwave determination of the mechanical strains in glass-reinforced plastic articles. Polym Mech 1976;11:7859.

[75] Shafi KTM, Saif ur Rahman M, Abou-Khousa MA, Ramzi MR. Applied microwave imaging of composite structures using open-ended circular waveguide. 2017 IEEE Int. Conf. Imaging Syst. Tech., IEEE; 2017, p. 1-5.

[76] Saif ur Rahman M, Yassin A, Abou-Khousa MA. Microwave imaging of thick composite structures using circular aperture probe. Meas Sci Technol 2018;29:095403. 
[77] Wang P, Pei Y, Zhou L. Near-field microwave identification and quantitative evaluation of liquid ingress in honeycomb sandwich structures. NDT E Int $2016 ; 83: 32-7$.

[78] Valiente LA, Haigh AD, Gibson AAP, Parkinson G, Jacobs G, Withers PJ, et al. Coplanar waveguide scanning microwave profiler. Proc. 37th Eur. Microw. Conf. EUMC, IEEE; 2007, p. 194-7.

[79] Albishi A, Ramahi OM. Detection of surface and subsurface cracks in metallic and non-metallic materials using a complementary split-ring resonator. Sensors (Switzerland) 2014;14:19354-70.

[80] Mukherjee S, Shi X, Udpa L, Udpa S, Deng Y, Chahal P. Design of a Split-Ring Resonator Sensor for Near-Field Microwave Imaging. IEEE Sens J 2018;18:7066-76.

[81] Mukherjee S, Tamburrino A, Haq M, Udpa S, Udpa L. Far field microwave NDE of composite structures using time reversal mirror. NDT E Int., vol. 93, AIP Publishing; 2018, p. 7-17.

[82] Moll J, Arnold P, Mälzer M, Krozer V, Pozdniakov D, Salman R, et al. Radarbased structural health monitoring of wind turbine blades: The case of damage detection. Struct Heal Monit 2018;17:815-22.

[83] Viegas C, Alderman B, Huggard PG, Powell J, Parow-Souchon K, Firdaus M, et al. Active Millimeter-Wave Radiometry for Nondestructive Testing/Evaluation of Composites - Glass Fiber Reinforced Polymer. IEEE Trans Microw Theory Tech 2017;65:641-50.

[84] Kharkovsky SN, Hepburn FL, Walker JL, Zoughi R. Nondestructive testing of the space shuttle external tank foam insulation using near field and focused 
millimeter wave techniques. Mater Eval 2005;63:516-22.

[85] A JTC. Microwave and Millimeter Wave Imaging Using Synthetic Aperture Focusing and Holographical Techniques Joseph. University of Missouri-Rolla, 2005.

[86] Sheen DM, McMakin DL, Hall TE. Three-dimensional millimeter-wave imaging for concealed weapon detection. IEEE Trans Microw Theory Tech 2001;49:1581-92.

[87] Wang Y, Burnett TL, Chai Y, Soutis C, Hogg PJ, Withers PJ. X-ray computed tomography study of kink bands in unidirectional composites. Compos Struct $2017 ; 160: 917-24$.

[88] Case JT, Kharkovsky S, Zoughi R, Steffes G, Hepburn FL. Millimeter wave holographical inspection of honeycomb composites. AIP Conf. Proc., vol. 975, AIP; 2008, p. 970-5.

[89] Yu B, Bradley RS, Soutis C, Withers PJ. A comparison of different approaches for imaging cracks in composites by X-ray microtomography. Philos Trans R Soc A Math Phys Eng Sci 2016;374:20160037.

[90] Büyüköztürk O, Yu T-Y. Far-field radar NDT technique for detecting GFRP debonding from concrete. Constr Build Mater 2009;23:1678-89.

[91] Meier D, Zech C, Baumann B, Hulsmann A, Link T, Schlechtweg M, et al. Detection of dry fiber fabric in glass fiber reinforced plastics using a focused Wband radar. 2018 11th Ger. Microw. Conf., IEEE; 2018, p. 387-90.

[92] Nezadal M, Schur J, Schmidt L-P. Imaging System for Non-Destructive Testing of Glass Fibre Reinforced Plastics. 5th Int. Symp. NDT Aerosp., Singapore: 2013, p. 1-5. 
[93] Nezadal M, Schur J, Schmidt L-P. Non-destructive testing of glass fibre reinforced plastics with a full polarimetric imaging system. 2014 39th Int. Conf. Infrared, Millimeter, Terahertz waves, IEEE; 2014, p. 1-2.

[94] Sheen D, McMakin D, Hall T. Near-field three-dimensional radar imaging techniques and applications. Appl Opt 2010;49:E83-93.

[95] Sheen DM, Hall TE, McMakin DL, Jones AM, Tedeschi JR. Three-dimensional radar imaging techniques and systems for near-field applications. In: Ranney KI, Doerry A, editors. vol. 9829, International Society for Optics and Photonics; 2016, p. 98290 V.

[96] Zhang H, Yang R, He Y, Foudazi A, Cheng L, Tian G. A review of microwave thermography nondestructive testing and evaluation. Sensors (Switzerland) 2017; $17: 1123$.

[97] Salski B, Olszewska-Placha M, Karpisz T, Rudnicki J, Gwarek W, Maliszewski M, et al. Microwave Applicator for Thermal Treatment of Bituminous Surfaces. IEEE Trans Microw Theory Tech 2017;65:3419-27.

[98] Swiderski W, Szabra D, Wojcik J. Nondestructive evaluation of aircraft components by thermography using different heat sources. Proc. 2002 Int. Conf. Quant. InfraRed Thermogr., QIRT Council; 2002, p. 79-84.

[99] Thostenson ET, Chou TW. Microwave processing: fundamentals and applications. Compos Part A Appl Sci Manuf 1999;30:1055-71.

[100] Ahlbom A, Bergqvist U, Bernhardt JH, Cesarini JP, Court LA, Grandolfo M, et al. Guidelines for limiting exposure to time-varying electric, magnetic, and electromagnetic fields (up to $300 \mathrm{GHz}$ ). Health Phys 1998;74:494-522. 
[101] Cheng L, Tian GY, Szymanik B. Feasibility studies on microwave heating for nondestructive evaluation of glass fibre reinforced plastic composites. 2011 IEEE Int. Instrum. Meas. Technol. Conf., IEEE; 2011, p. 1-6.

[102] Chady T. Wind Turbine Blades Inspection Techniques. Przegląd Elektrotechniczny 2016;1:3-6.

[103] Bakhtiari S, Ganchev SI, Zoughi R. Open-Ended Rectangular Waveguide for Nondestructive Thickness Measurement and Variation Detection of Lossy Dielectric Slabs Backed by a Conducting Plate. IEEE Trans Instrum Meas $1993 ; 42: 19-24$.

[104] Sayar M, Seo D, Ogawa K. Non-destructive microwave detection of layer thickness in degraded thermal barrier coatings using $\mathrm{K}$ - and $\mathrm{W}$-band frequency range. NDT E Int 2009;42:398-403.

[105] Zoughi R, Gallion JR, Ghasr MT. Accurate Microwave Measurement of Coating Thickness on Carbon Composite Substrates. IEEE Trans Instrum Meas 2016;65:951-3.

[106] Ghasr MT, Horst MJ, Lechuga M, Rapoza R, Renoud CJ, Zoughi R. Accurate One-Sided Microwave Thickness Evaluation of Lined-Fiberglass Composites. IEEE Trans Instrum Meas 2015;64:2802-12.

[107] Takeuchi JS, Perque M, Anderson P, Sergoyan EG. Microwave paint thickness sensor. U.S. 7,898,265, 2011.

[108] Boybay MS, Ramahi OM. Non-destructive thickness measurement using quasistatic resonators. IEEE Microw Wirel Components Lett 2013;23:217-9.

[109] Bahr AJ. Microwave nondestructive testing methods. 1st ed. New York, NY: Gordon and Breach Science Publishers; 1982. 
[110] Govind G, Tiwari NK, Agrawal KK, Akhtar MJ. Microwave Subsurface Imaging of Composite Structures Using Complementary Split Ring Resonators. IEEE Sens J 2018;18:7442-9.

[111] Ghasr MT, Abou-Khousa MA, Kharkovsky S, Zoughi R, Pommerenke D. Portable real-time microwave camera at 24 GHz. IEEE Trans Antennas Propag 2012;60:1114-25.

[112] Zhong CH, Croxford AJ, Wilcox PD. Remote inspection system for impact damage in large composite structure. Proc R Soc A Math Phys Eng Sci 2014;471:20140631-20140631.

[113] Arcadius Tokognon C, Gao B, Tian GY, Yan Y. Structural Health Monitoring Framework Based on Internet of Things: A Survey. IEEE Internet Things J 2017;4:619-35.

[114] Carrigan TD, Forrest BE, Andem HN, Gui K, Johnson L, Hibbert JE, et al. Nondestructive Testing of Nonmetallic Pipelines Using Microwave Reflectometry on an In-Line Inspection Robot. IEEE Trans Instrum Meas 2018:1-9.

[115] Heuer H, Schulze M, Pooch M, Gäbler S, Nocke A, Bardl G, et al. Review on quality assurance along the CFRP value chain - Non-destructive testing of fabrics, preforms and CFRP by HF radio wave techniques. Compos Part B Eng 2015;77:494-501.

[116] Waller JM, Parker BH, Hodges KL, Burke ER, Walker JL. Nondestructive Evaluation of Additive Manufacturing State-of-the-Discipline Report. 2014.

[117] Dickson AN, Barry JN, McDonnell KA, Dowling DP. Fabrication of continuous carbon, glass and Kevlar fibre reinforced polymer composites using additive 
manufacturing. Addit Manuf 2017;16:146-52.

[118] Parandoush P, Lin D. A review on additive manufacturing of polymer-fiber composites. Compos Struct 2017;182:36-53.

[119] Hajisaeid E, Dericioglu AF, Akyurtlu A. All 3-D Printed Free-Space Setup for Microwave Dielectric Characterization of Materials. IEEE Trans Instrum Meas 2018:1-10. 


\section{Tables}

Table 1 Dielectric properties of some typical glass fibres at $10 \mathrm{GHz}$ at room temperature [23]

\begin{tabular}{|c|c|c|c|c|c|}
\hline & D Glass & E Glass & ECR Glass & R Glass & S-2 Glass \\
\hline$\varepsilon_{r}^{\prime}$ & 4.0 & 6.1 & 7.0 & - & 5.2 \\
\hline $\tan \delta\left(=\varepsilon_{r}^{\prime \prime} / \varepsilon_{r}^{\prime}\right)$ & 0.0026 & 0.0038 & 0.0031 & 0.0051 & 0.0068 \\
\hline
\end{tabular}

Table 2 Dielectric properties of some typical epoxy resins at room temperature

\begin{tabular}{|l|l|l|l|l|l|}
\hline & $828 / \mathrm{T} 403$ & Araldite F & Epikote Resin & LY 564/XB & \\
& $(1.0-2.5 \mathrm{GHz})$ & $(4.28 \mathrm{GHz})$ & 828 & 3486 & E44 \\
& {$[24]$} & {$[25]$} & $(8-12 \mathrm{GHz})[26]$ & {$[27-12 \mathrm{GHz})$} & {$[28]$} \\
{$\left[\varepsilon_{r}^{\prime}\right.$} & 3.456 & 3.14 & 3.1 & 2.74 & 2.95 \\
\hline $\tan \delta$ & 0.0012 & 0.035 & 0.032 & - & 0.034 \\
\hline
\end{tabular}




\section{Figure captions}

Fig. 1. Near- and far-field regions of an antenna (adapted from [35]).

Fig. 2. Two typical antenna configurations for far-field microwave inspection. (a) monostatic configuration. (b) bistatic configuration.

Fig. 3. Illustration of the transmission line method for permittivity measurement. (a) experimental setup. (b) test sample placed within the test cell. (c) coaxial line cell. (d) rectangular waveguide cell.

Fig. 4. Illustration of the open-ended probe method for permittivity measurement.

Fig. 5. Schematic diagram of the simulation-assisted approach for non-contact permittivity measurement with an open-ended waveguide [52].

Fig. 6. Illustration of the short-circuited line method where the sample is in the probe but short-circuited by a good conductor.

Fig. 7. Illustration of the free space method for electric permittivity measurement. (a) setup with two high-gain horn antennae only. (b) setup with dielectric lenses for focusing.

Fig. 8. Equivalent circuit model for near-field inspection with an open-ended probe. Fig. 9. Microwave detection of impact damage in a $10 \mathrm{~mm}$ thick GFRP sample. (a) front surface. (b) back surface. (c) image of the overall damage produced at $35 \mathrm{GHz}$ from scanning over the front (impacted) surface [70].

Fig. 10. Microwave inspection of delamination in a GFRP T-joint [33]. (a) locations of T-joints in a wind turbine blade. (b) photograph of the T-joint specimen. (c) experimental setup. (d) scan image of the magnitude. (e) scan image of the phase. 
Fig. 11. Experimental setup of the near-field microwave system for detection of liquid ingress in honeycomb sandwich structures [77].

Fig. 12. A general near-field microwave microscope $(\lambda / 4$ coaxial resonator) for surface profiling. (a) schematic diagram. (b) lumped circuit model.

Fig. 13. Far-field damage inspection using FMCW bistatic radars. (a) photograph of the cut $(60 \mathrm{~mm})$ in the GFRP plate (b) damage detection at $35 \mathrm{GHz}$.

Fig. 14. Block diagram of the focused radar measurement system including radar front end, offset parabolic mirrors and 3D movable stage [91].

Fig. 15. Schematic diagram of the experimental setup for microwave-based thermography. 


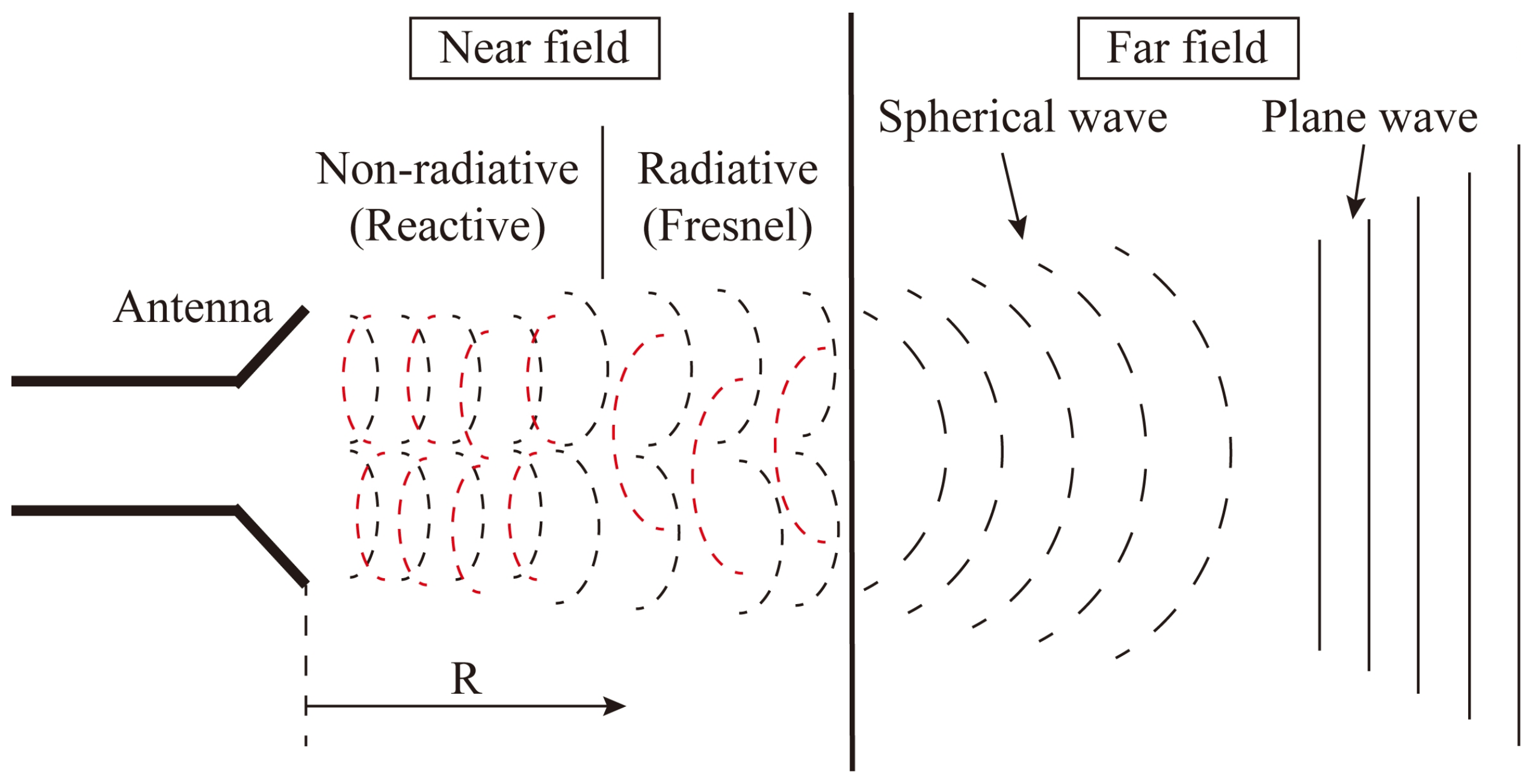




\section{Input signal}

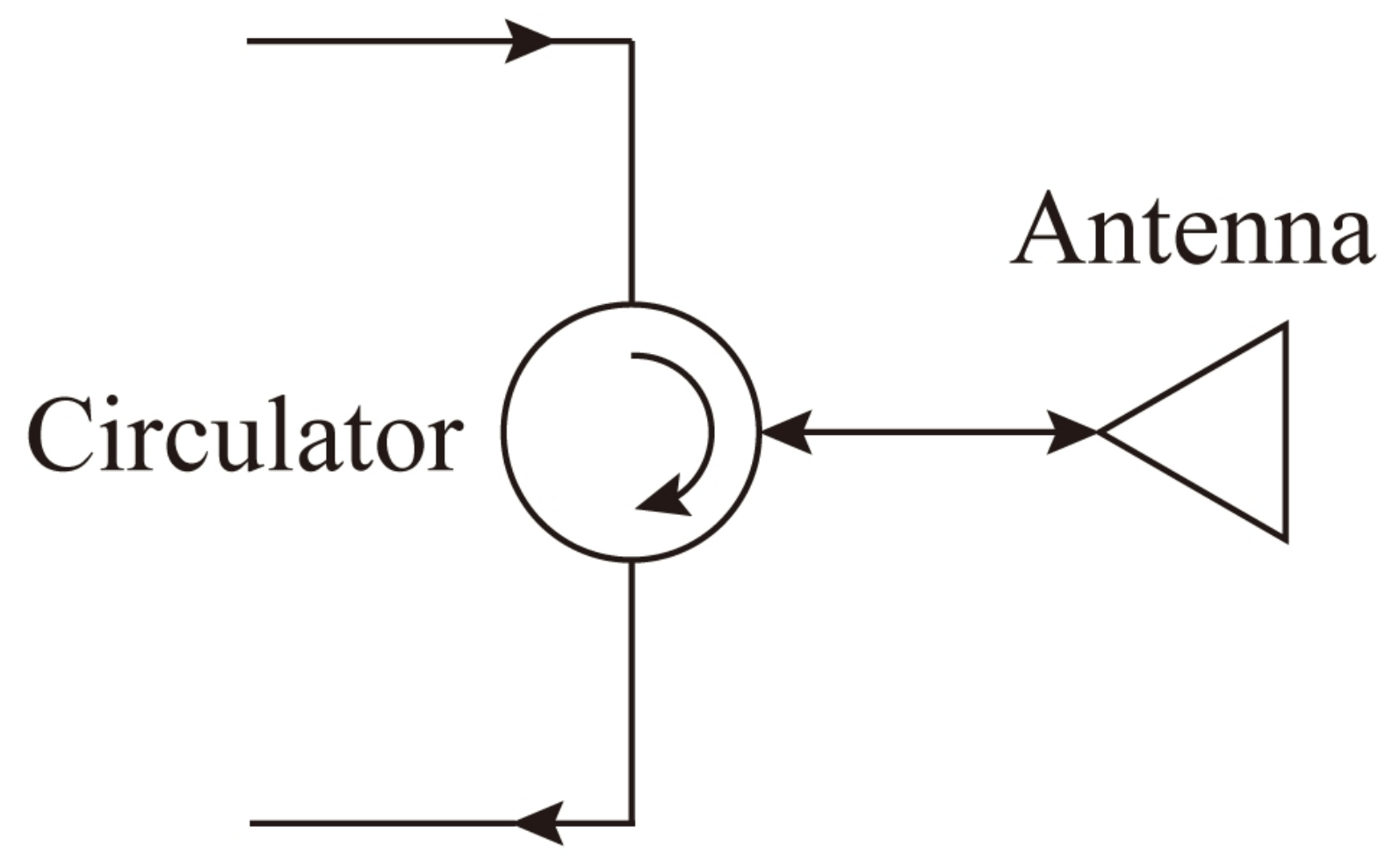

Output signal

\section{Sample}

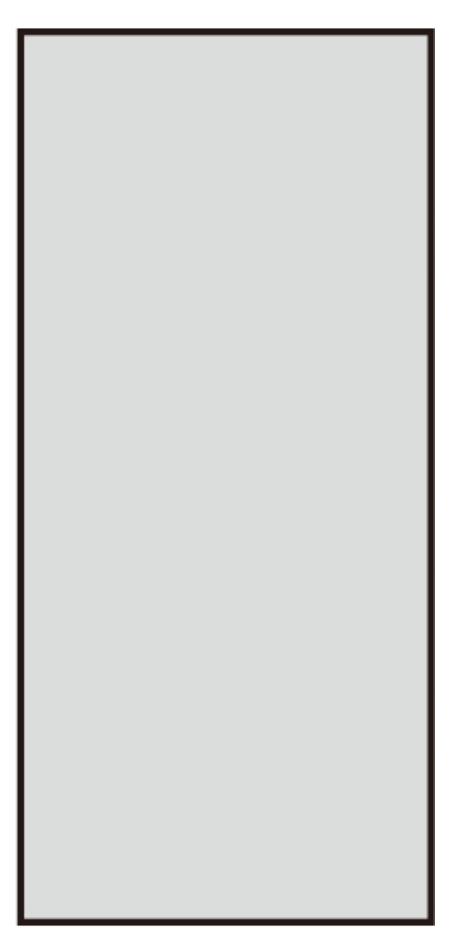




\section{Reflection mode}

Input signal
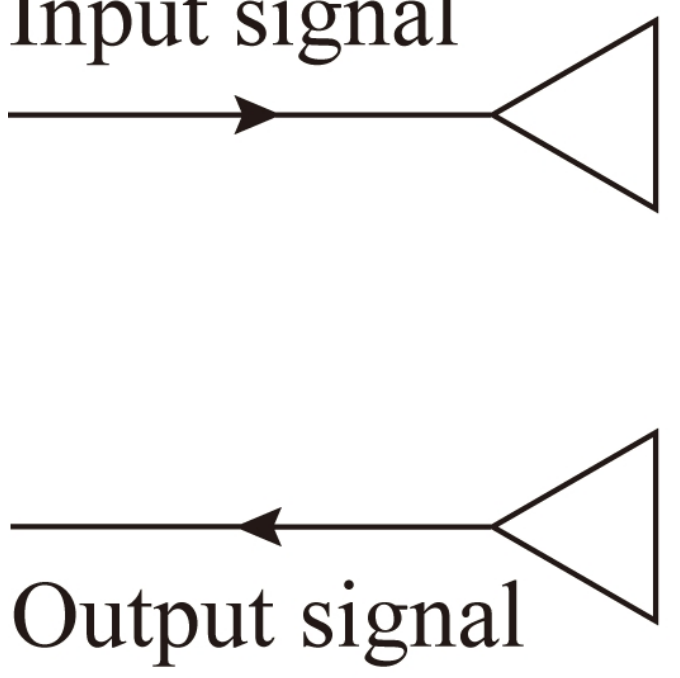

Transmission mode

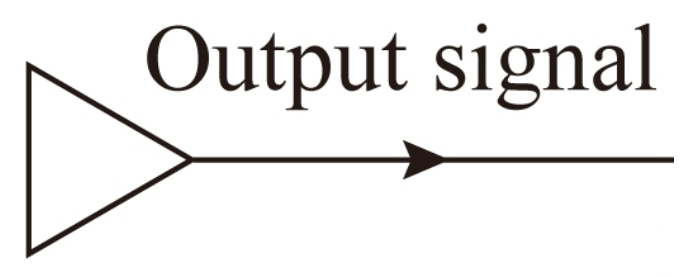




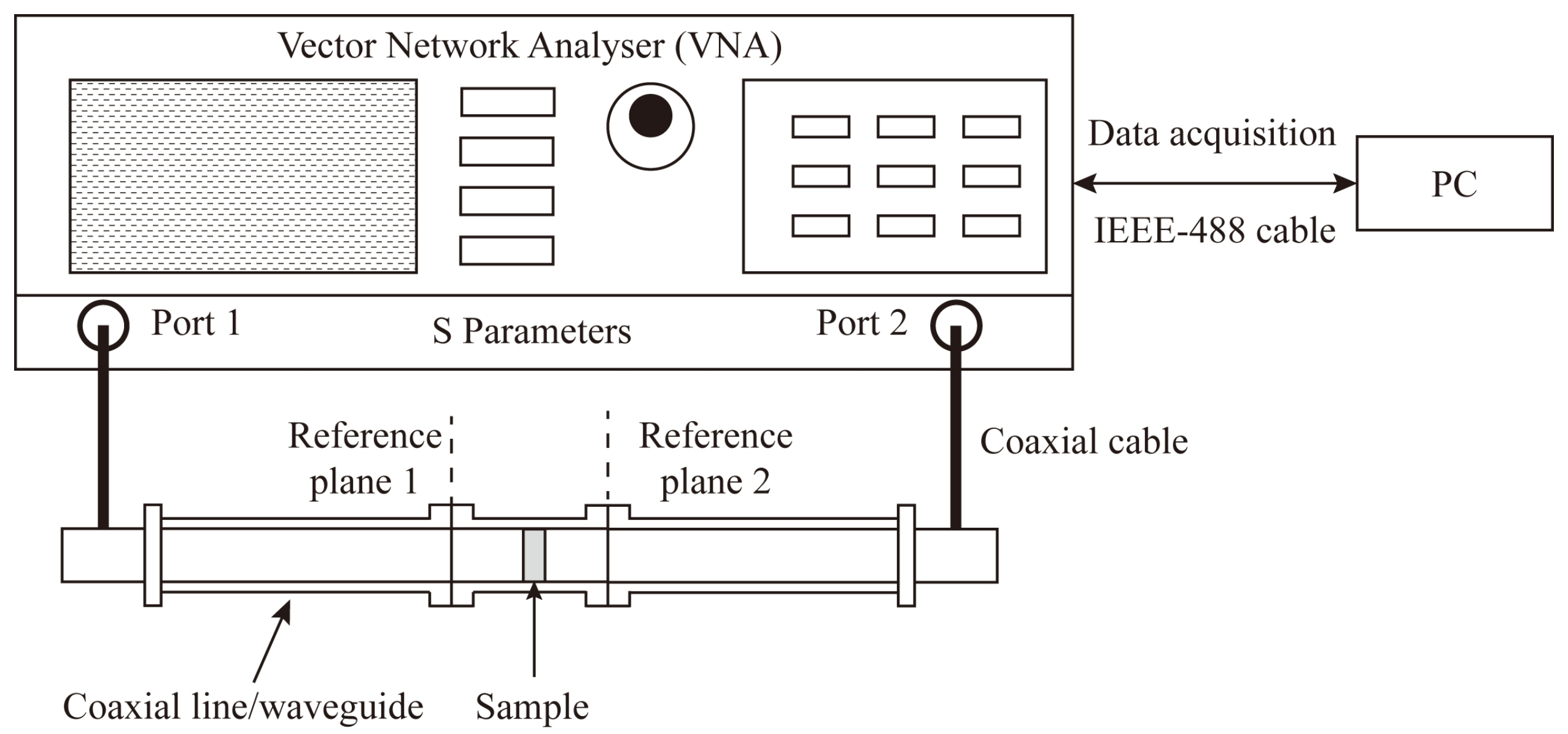




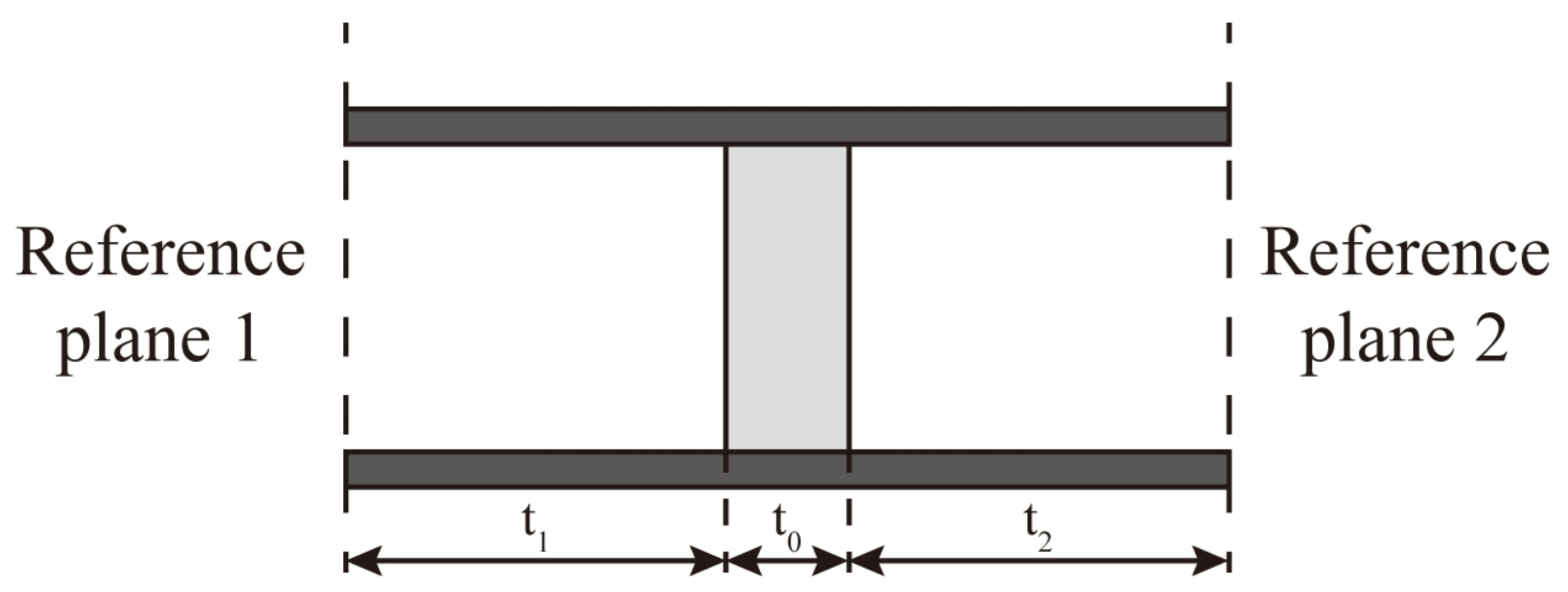




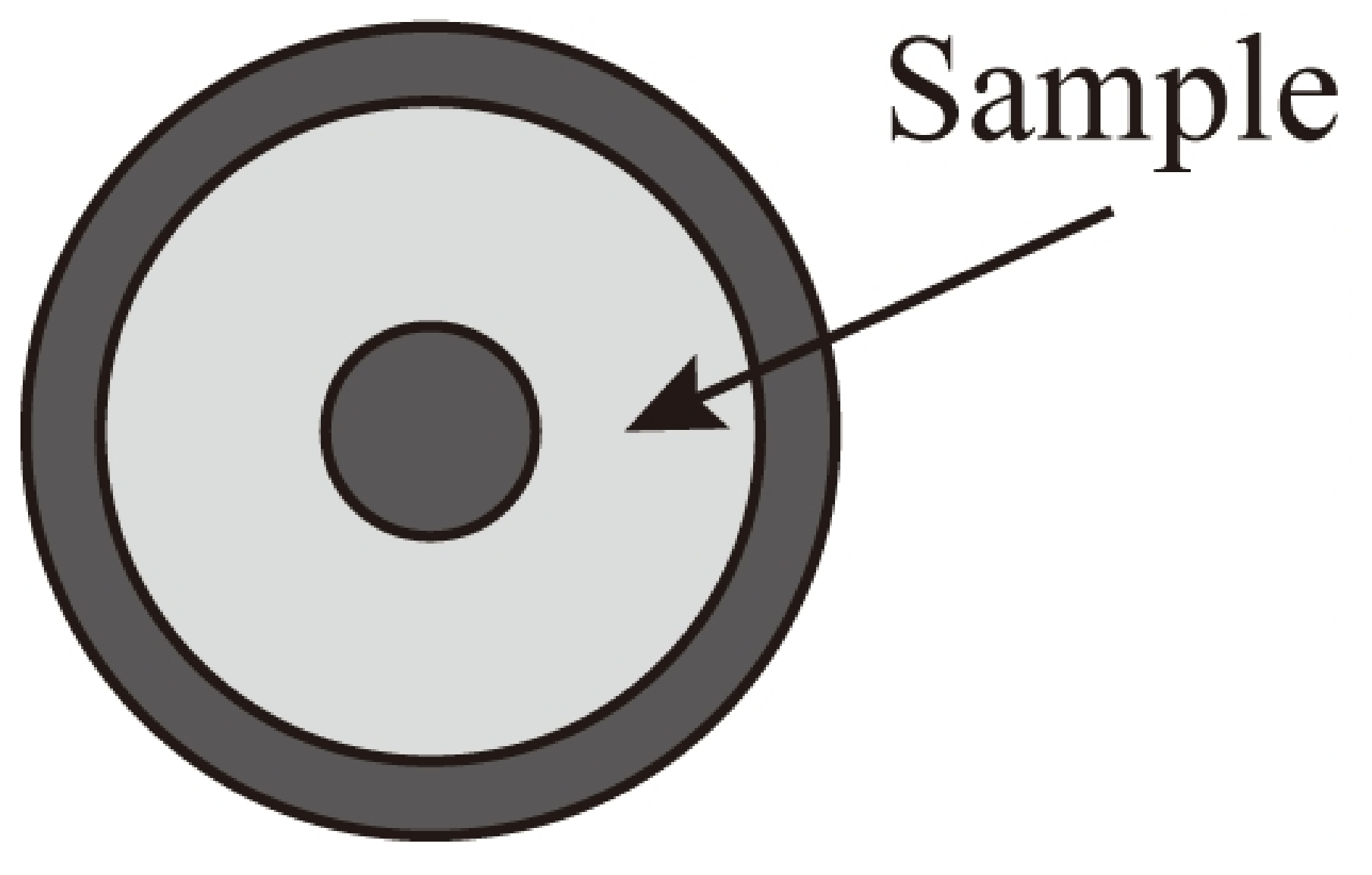




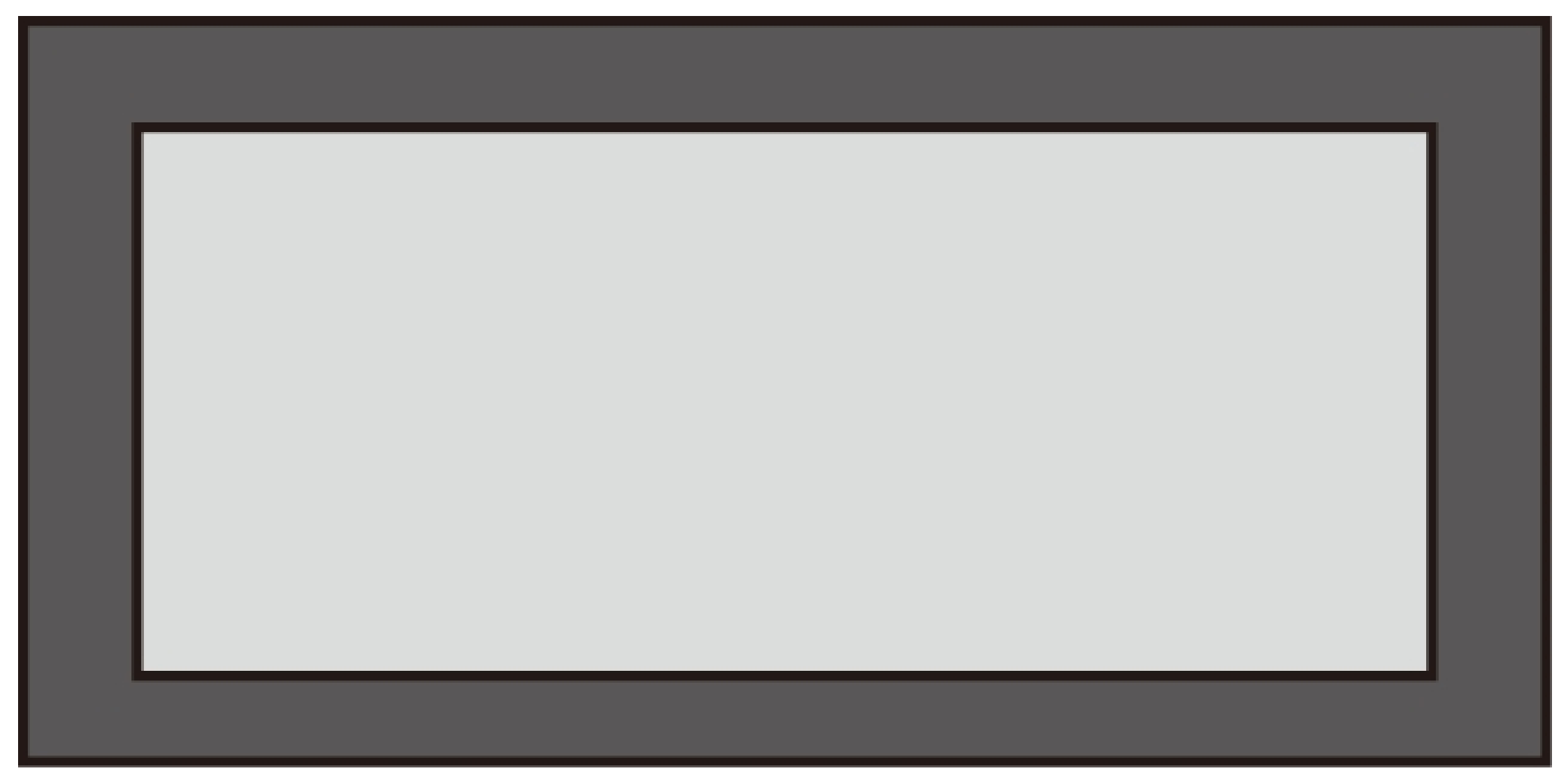




\section{Network \\ Probe (coaxial line/waveguide)}

analyser 
Open-ended

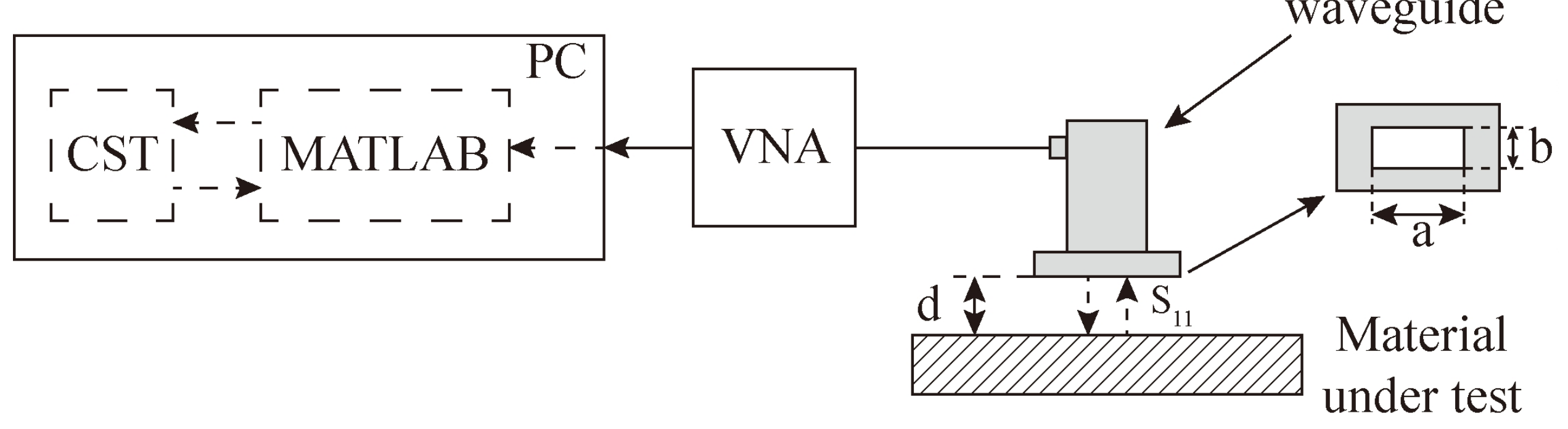




\section{Conductor}

Sample

Probe

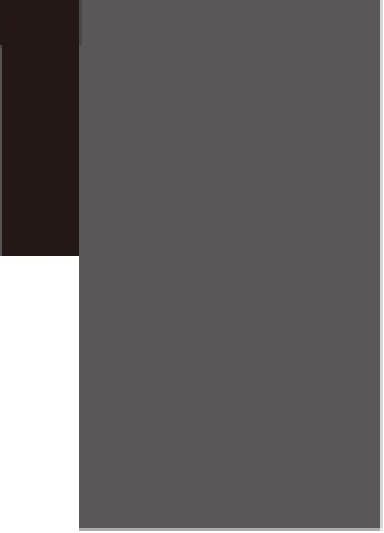



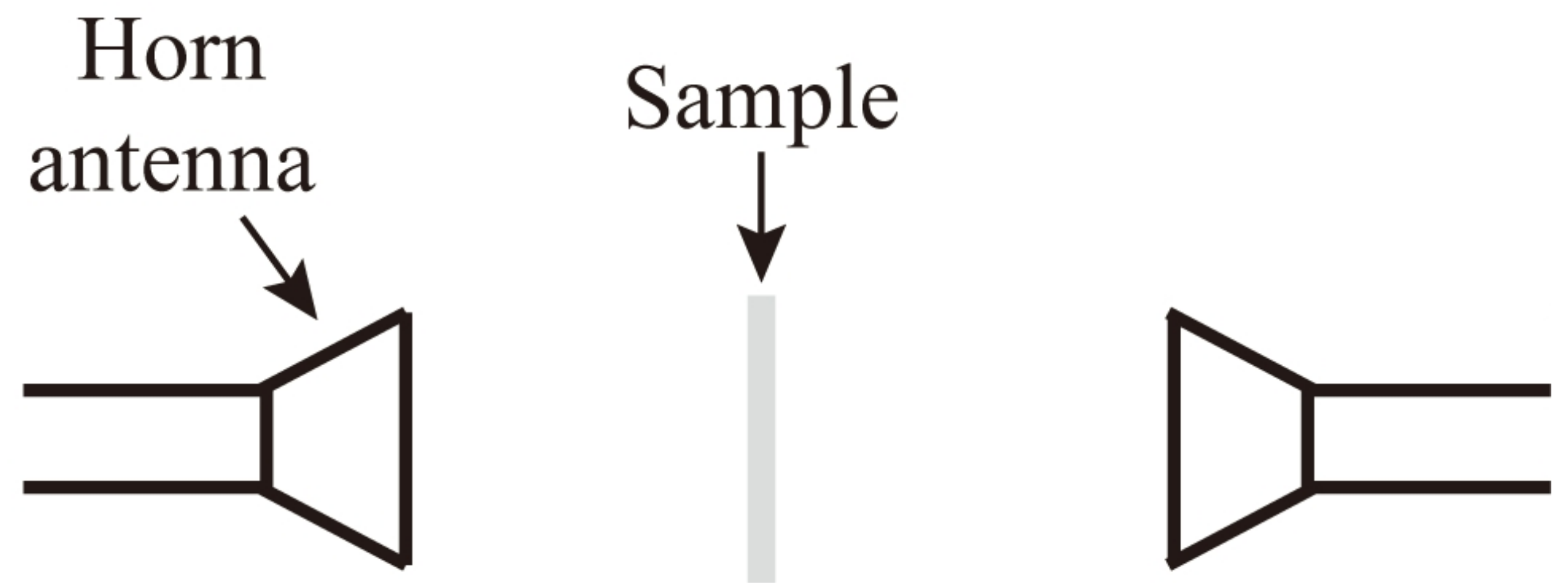


\section{Lens}

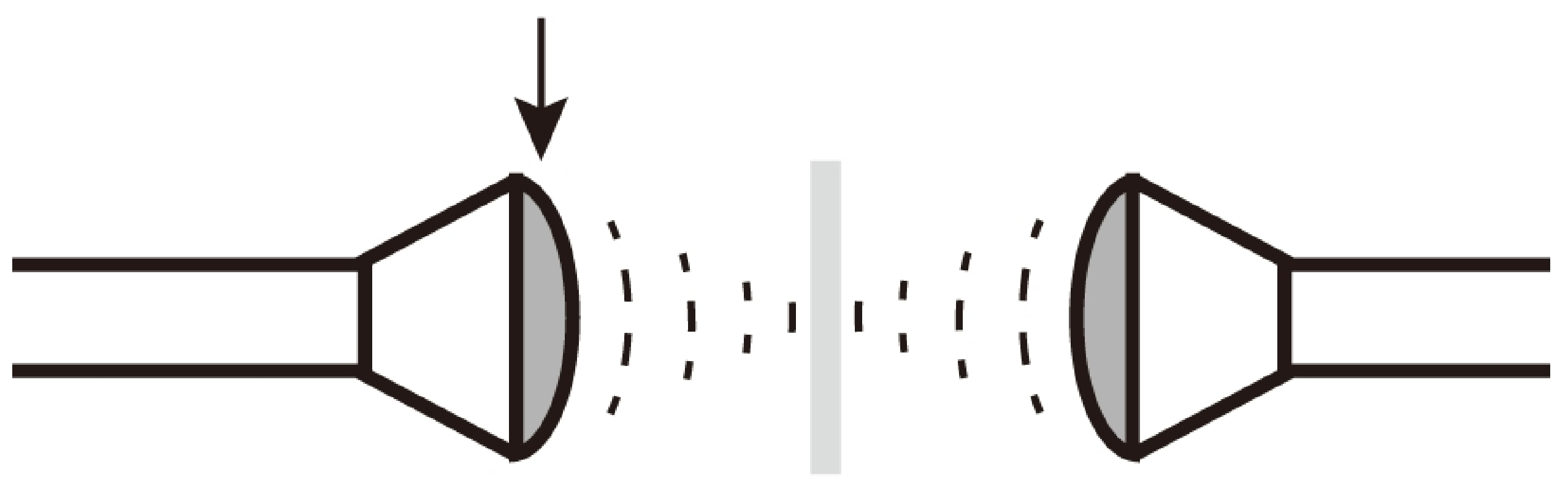




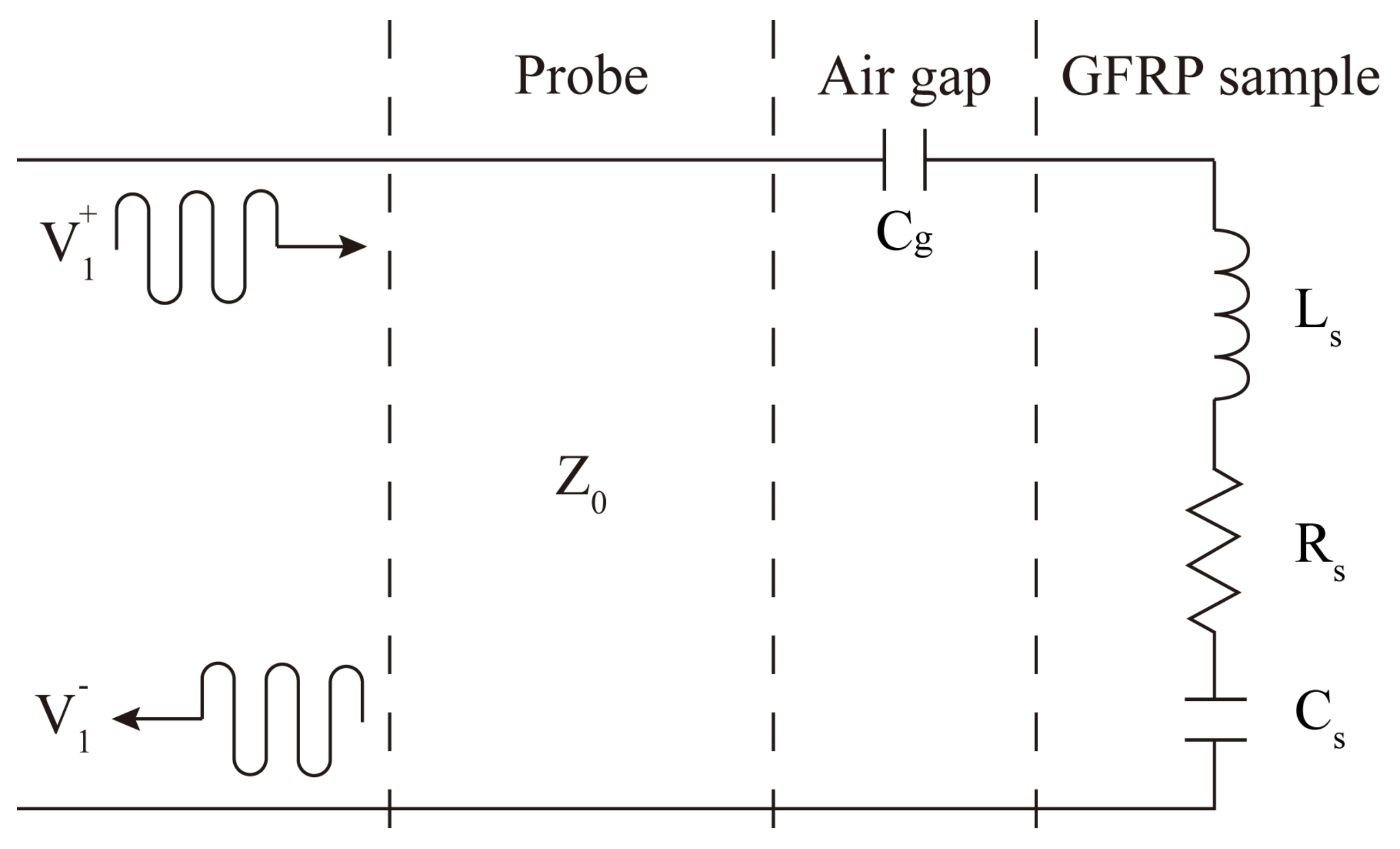




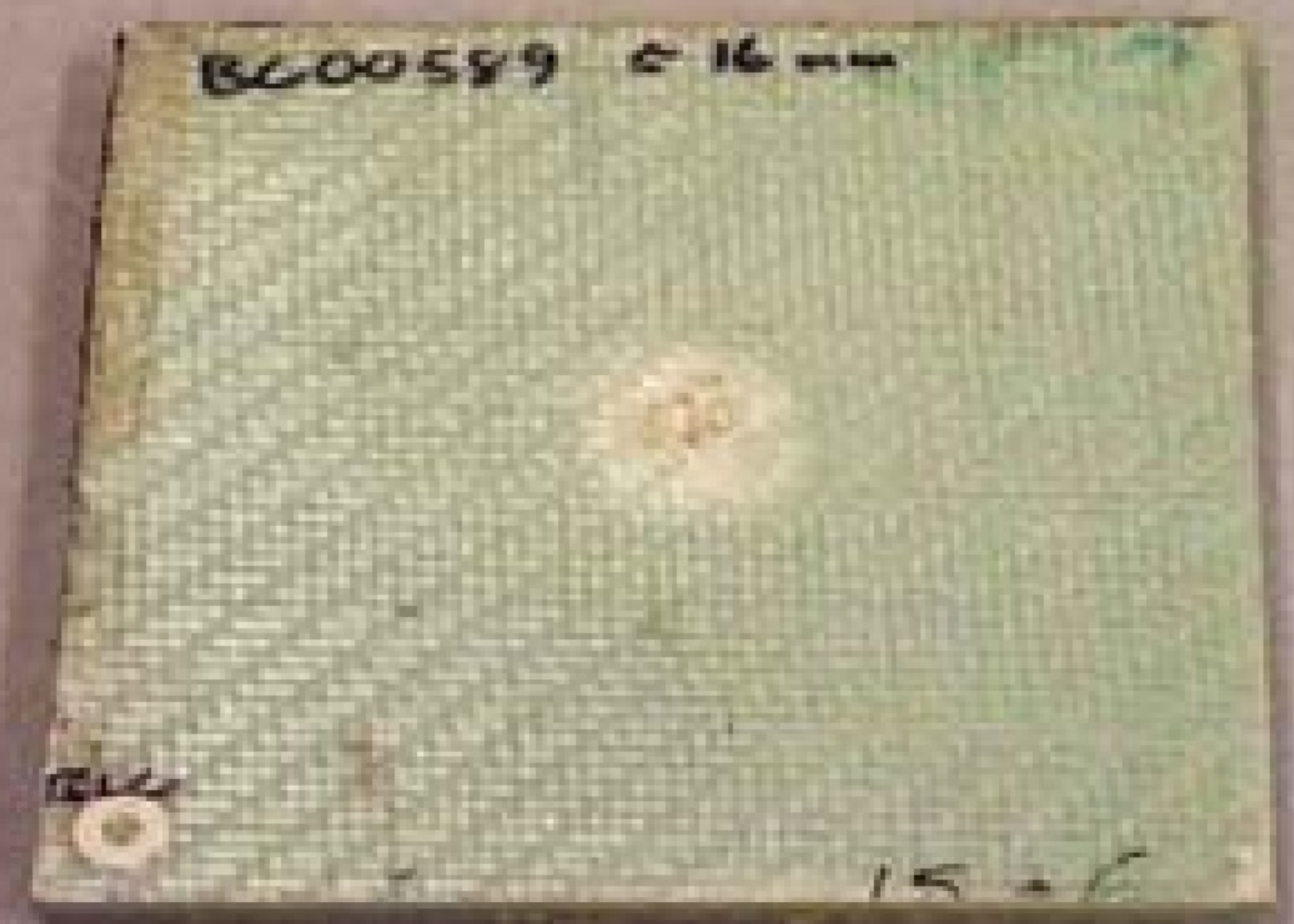




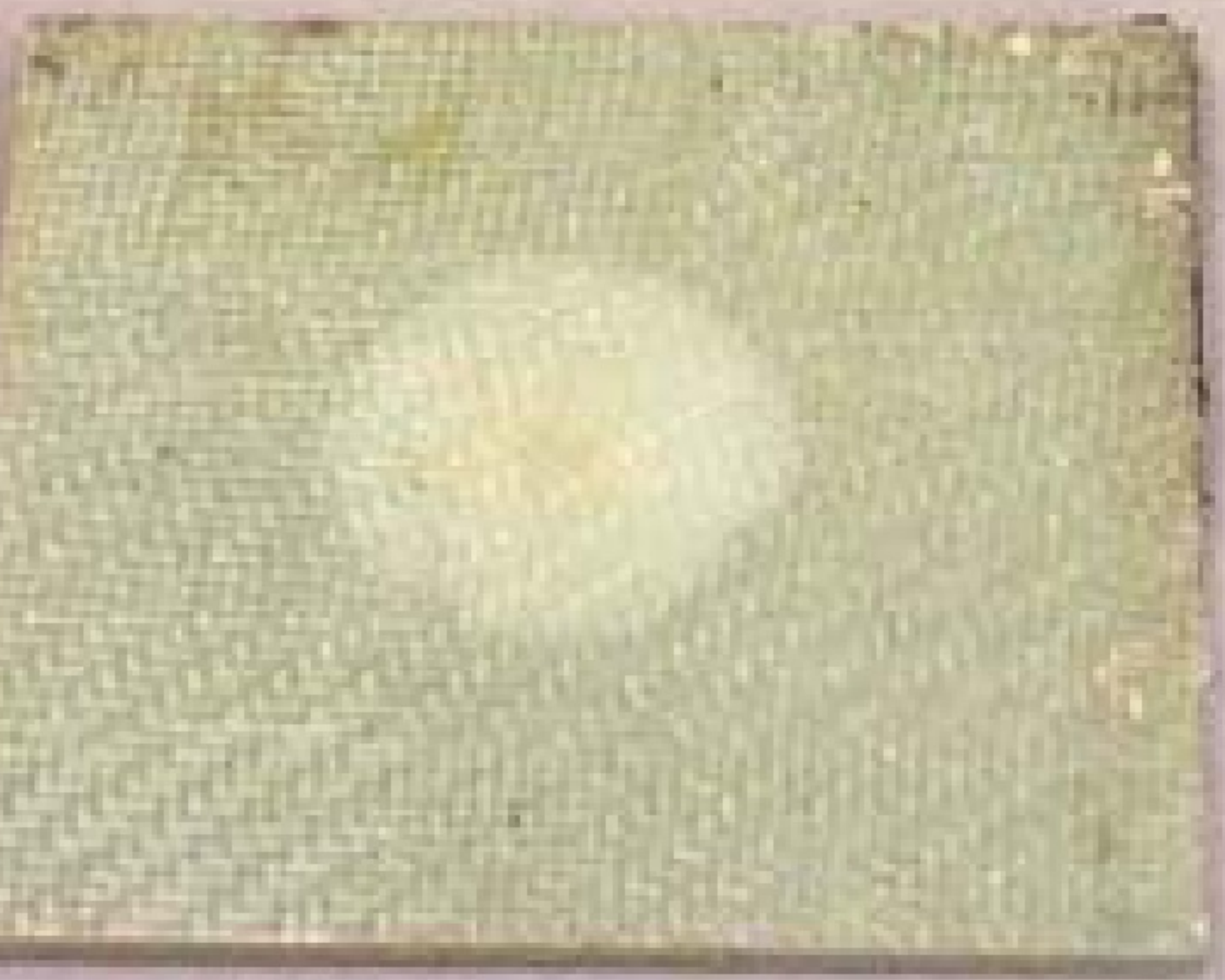




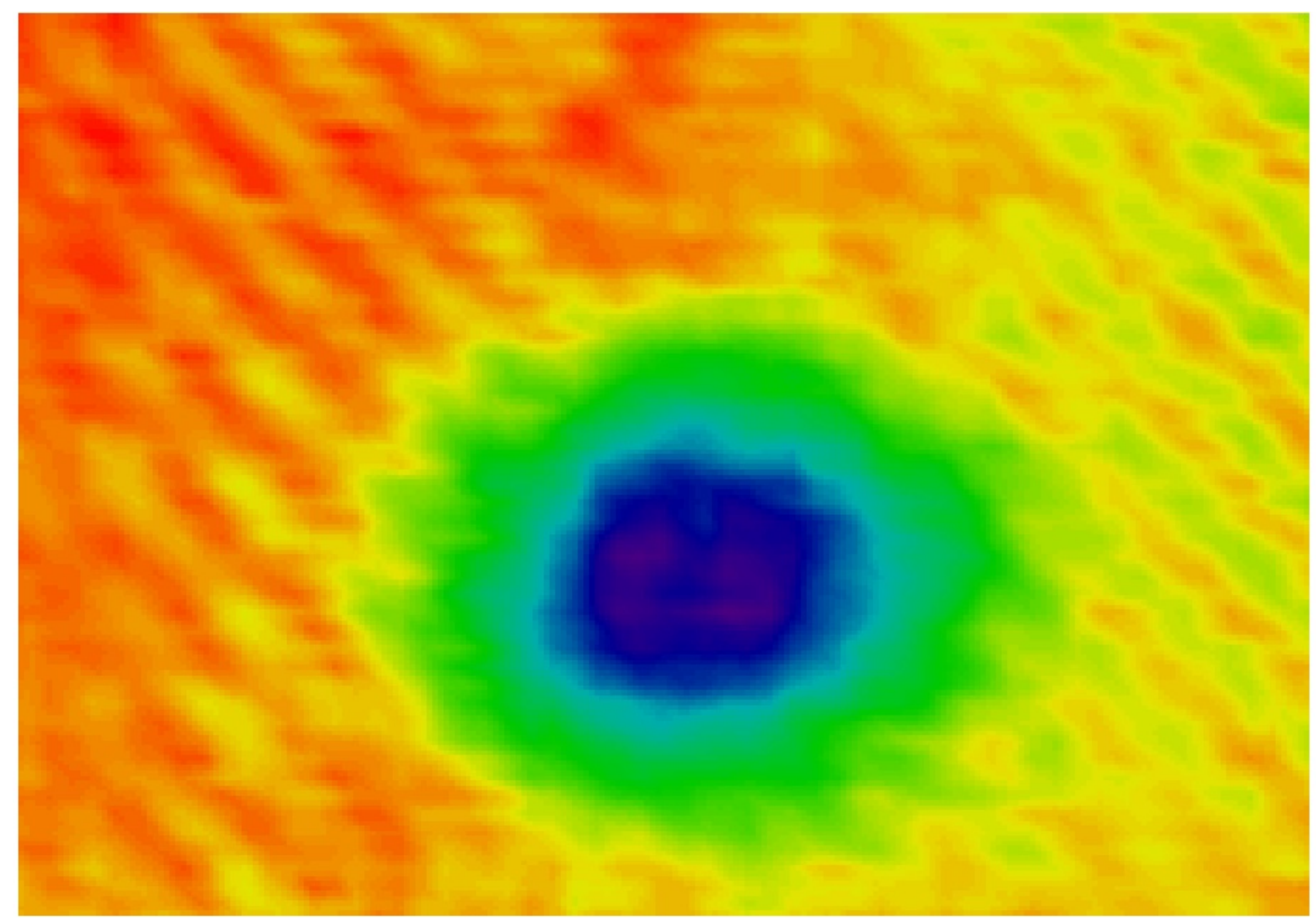




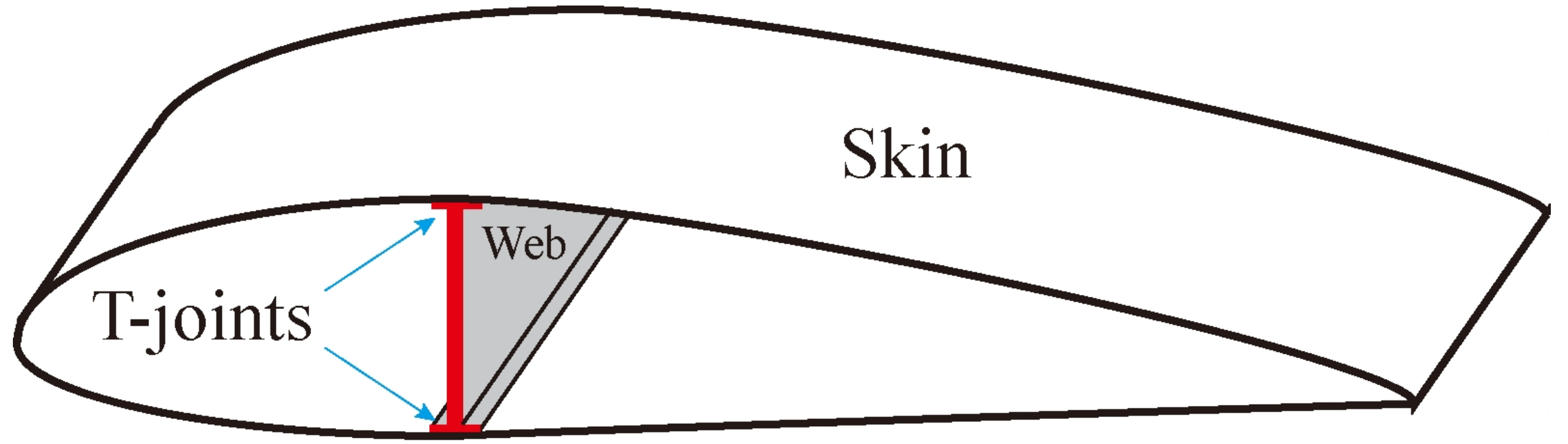




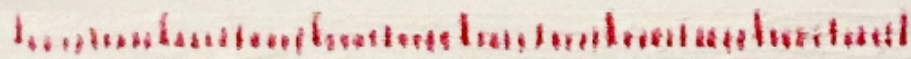

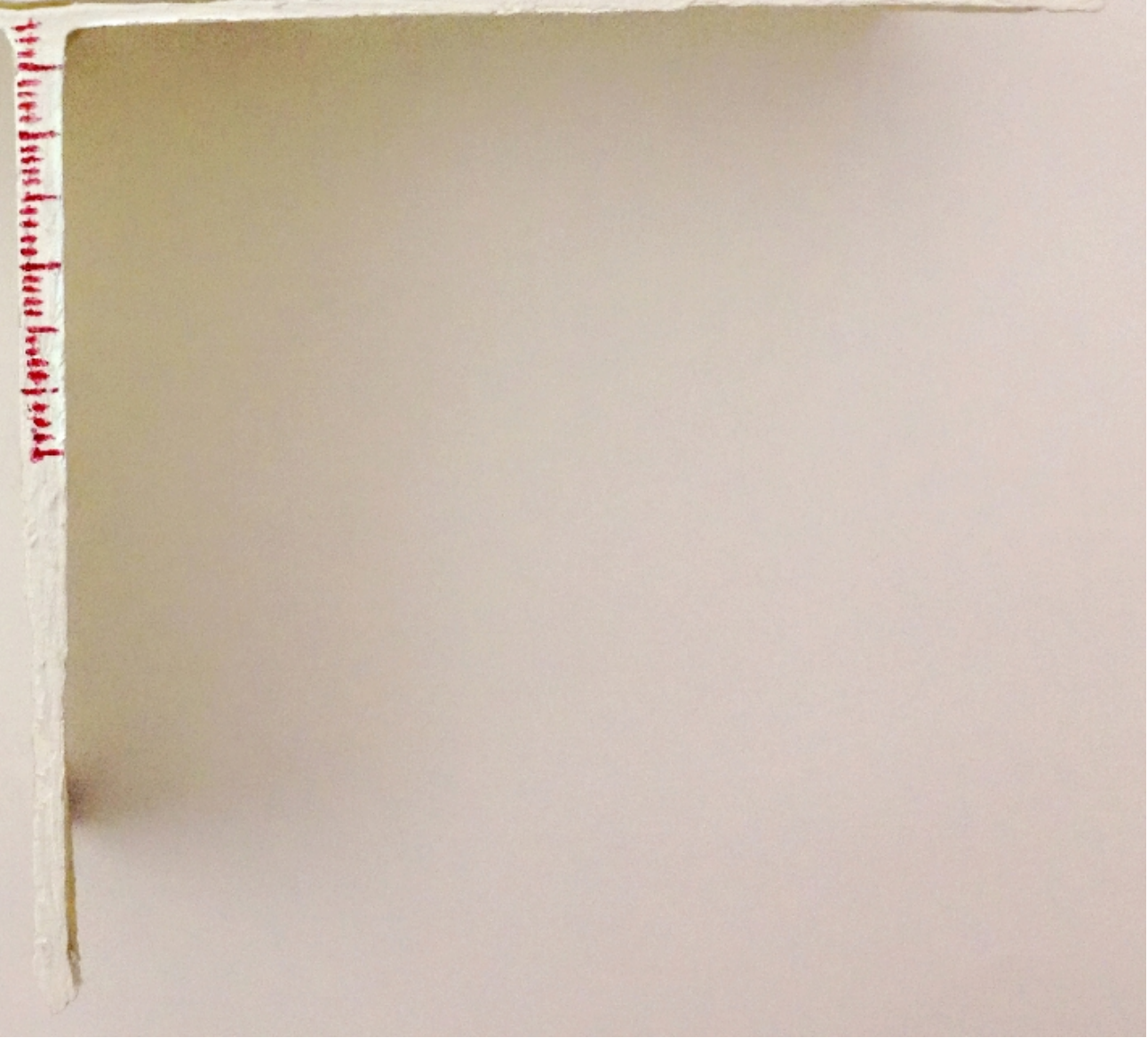




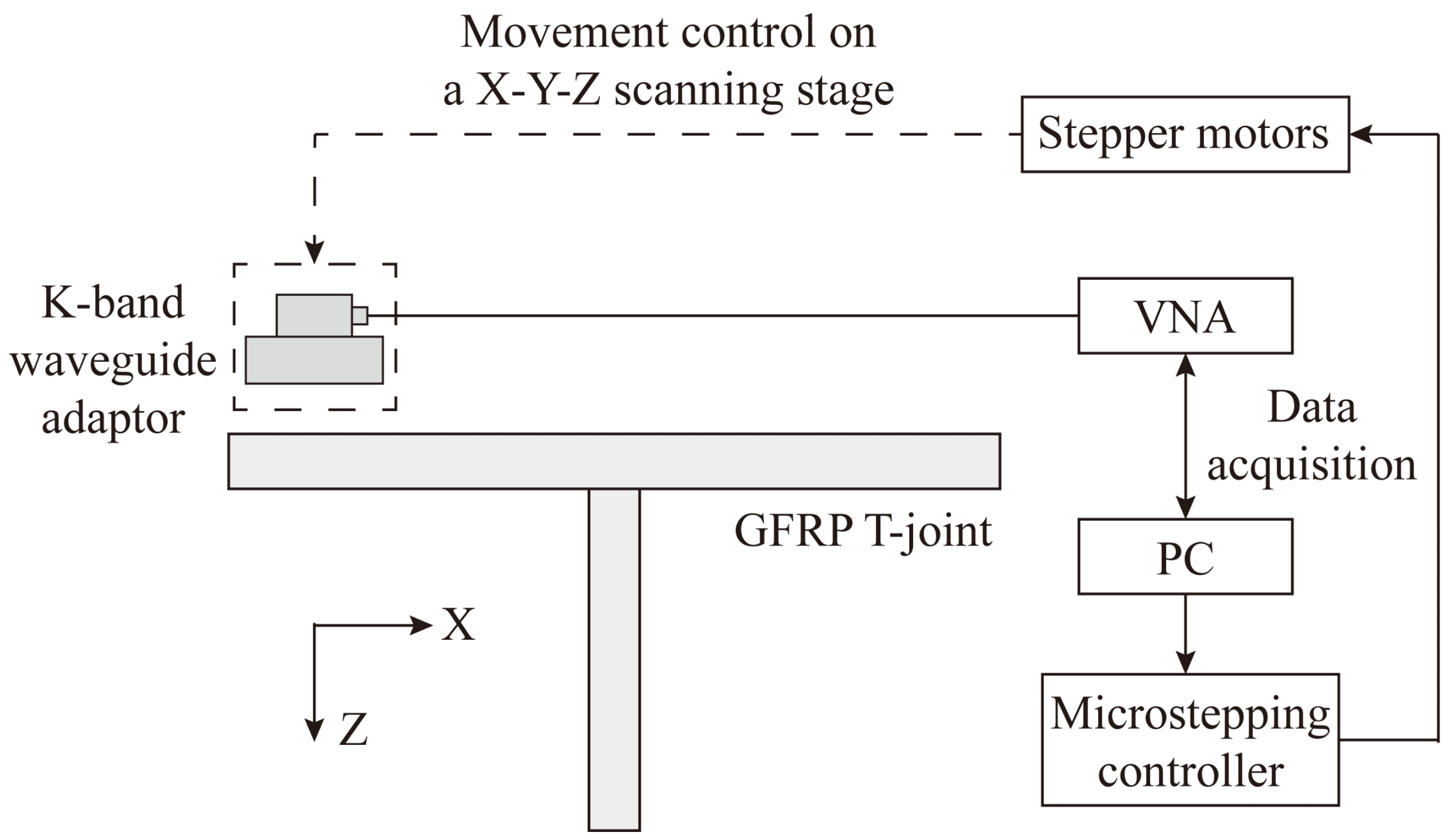


$\left|\mathrm{S}_{11}\right|(\mathrm{dB})$

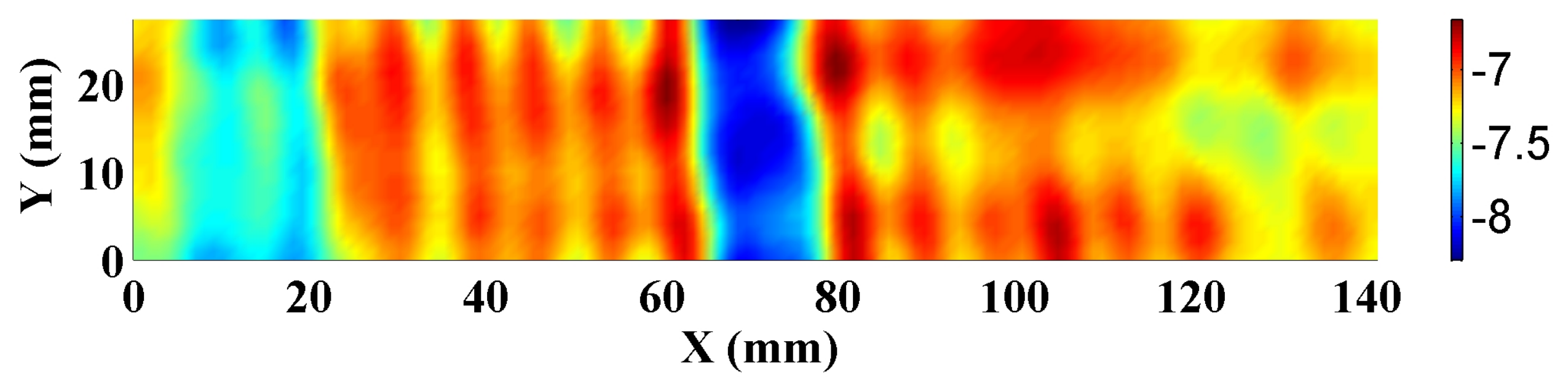




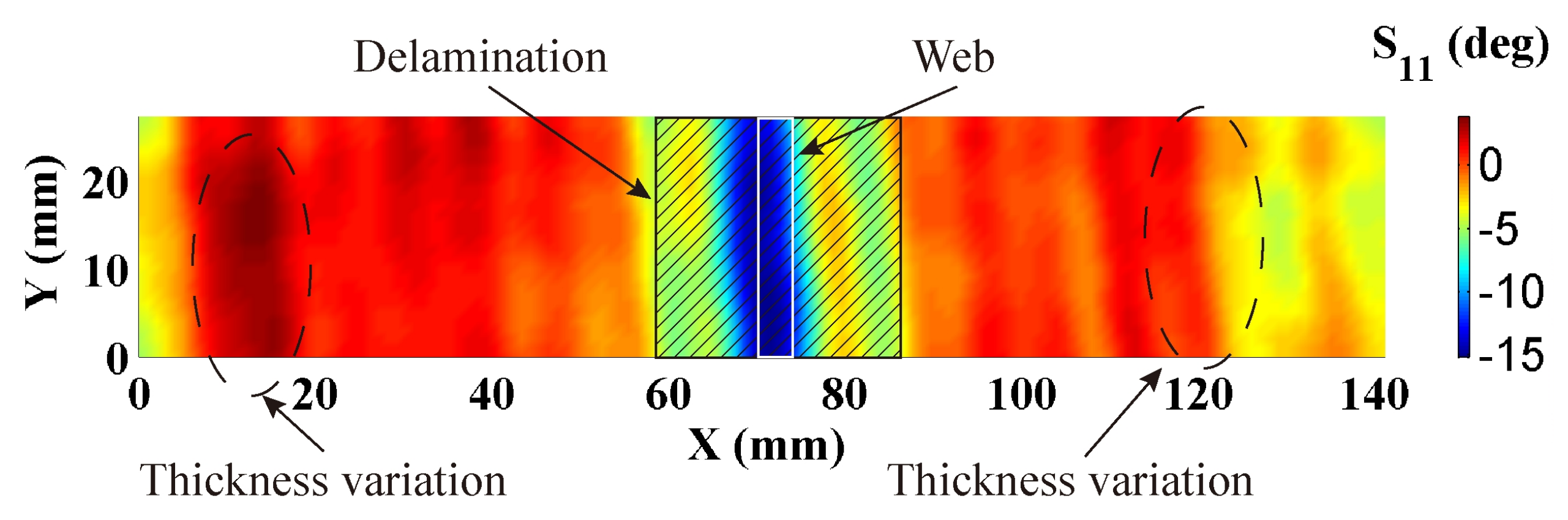




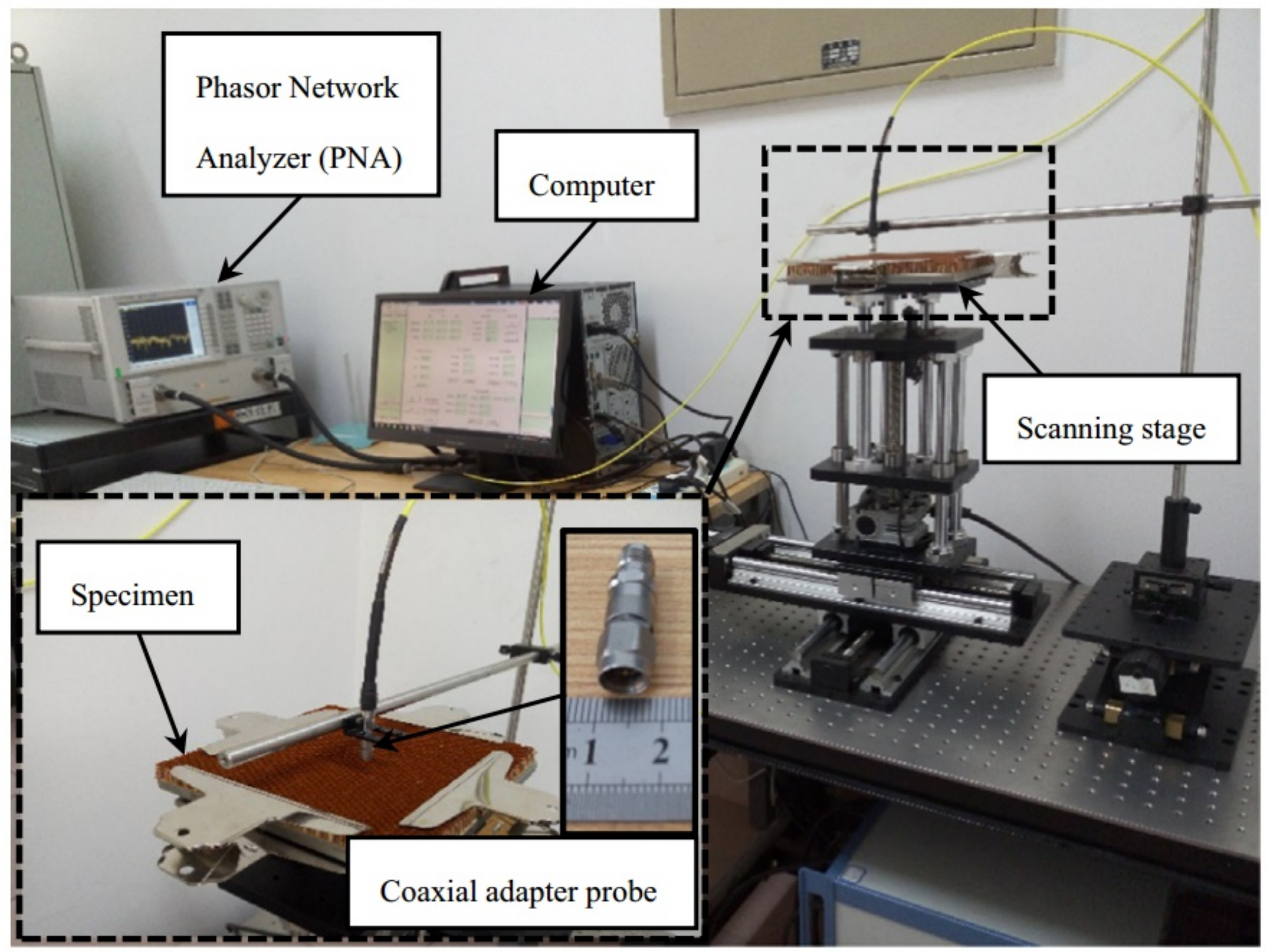



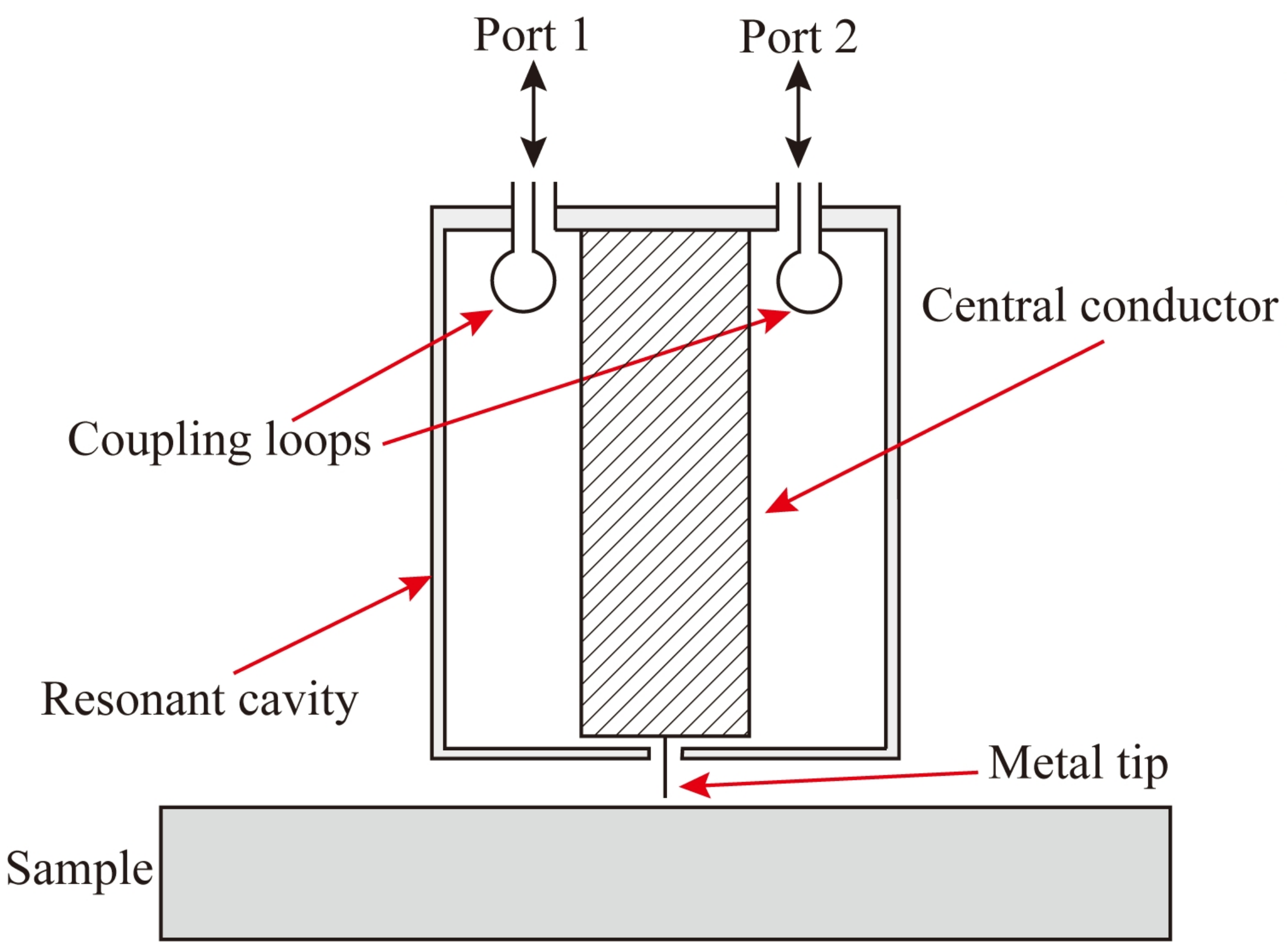


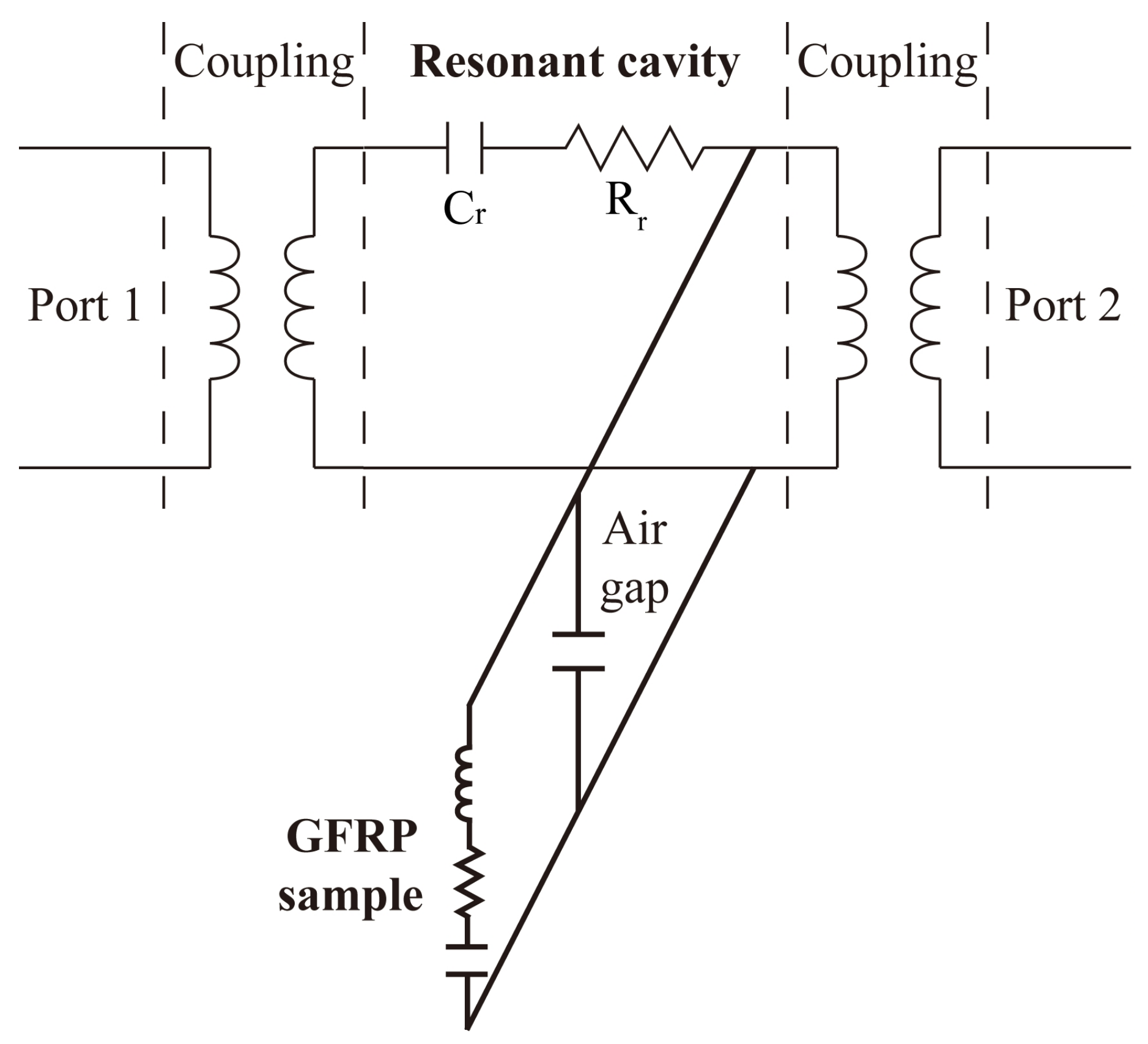




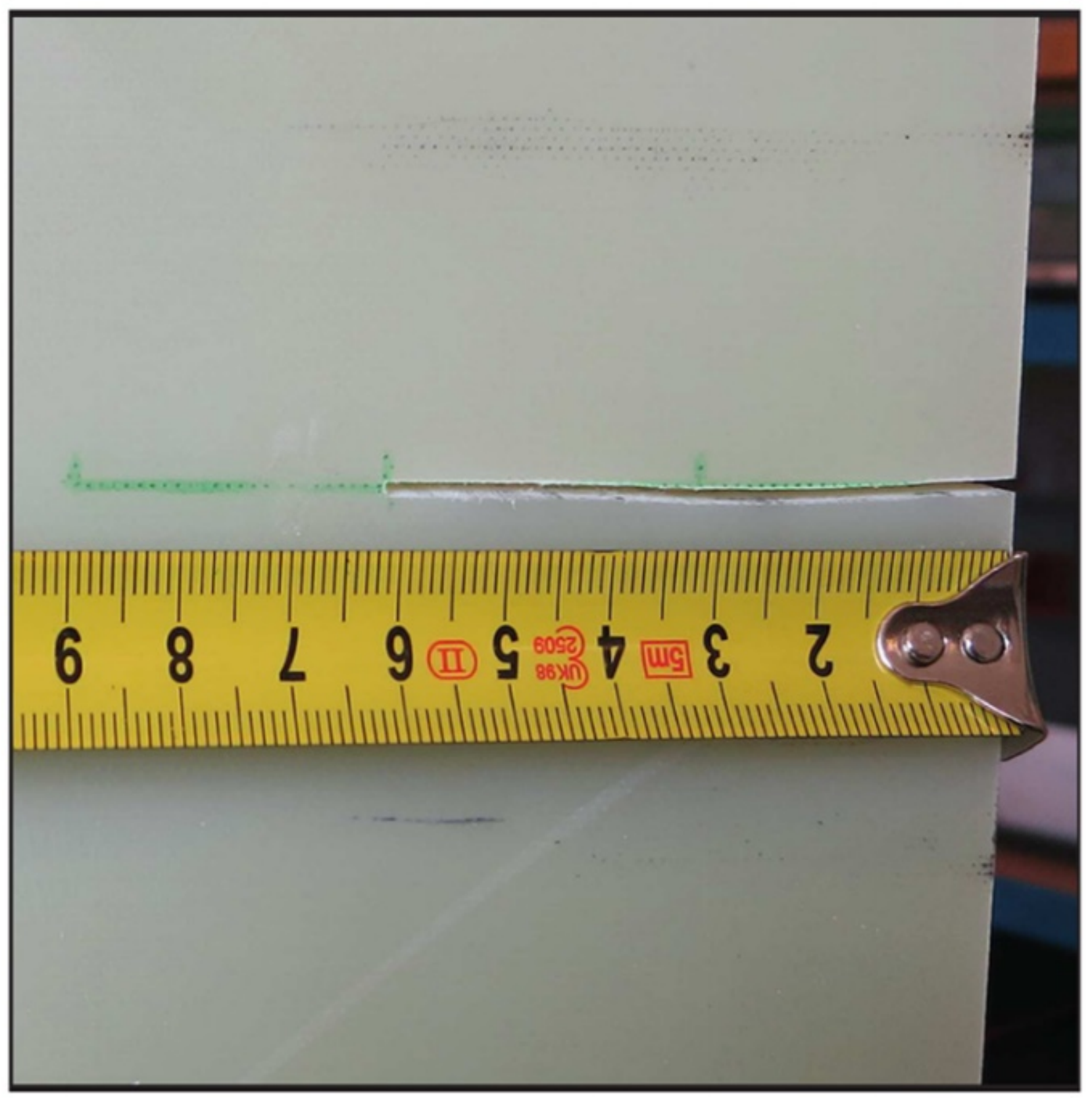




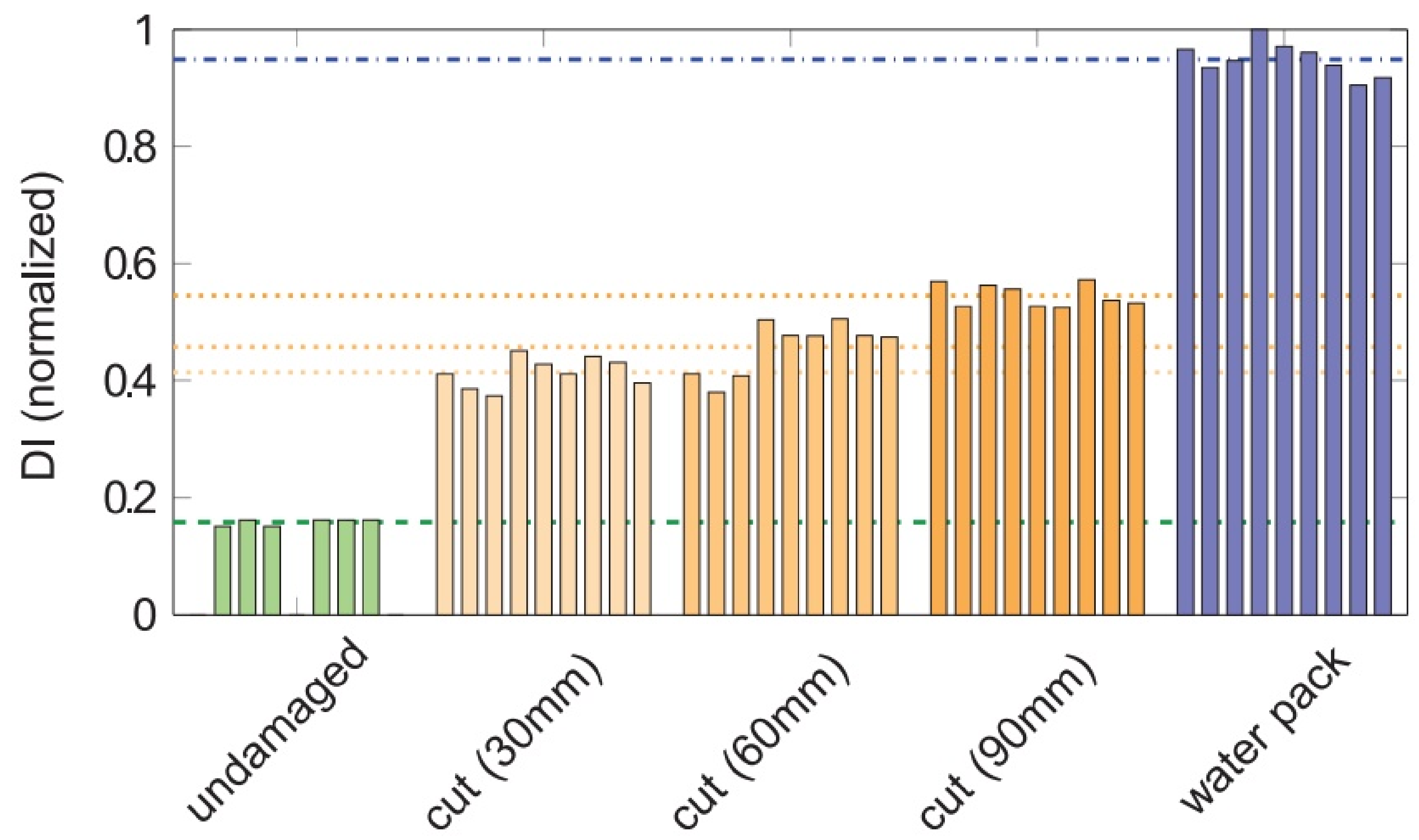




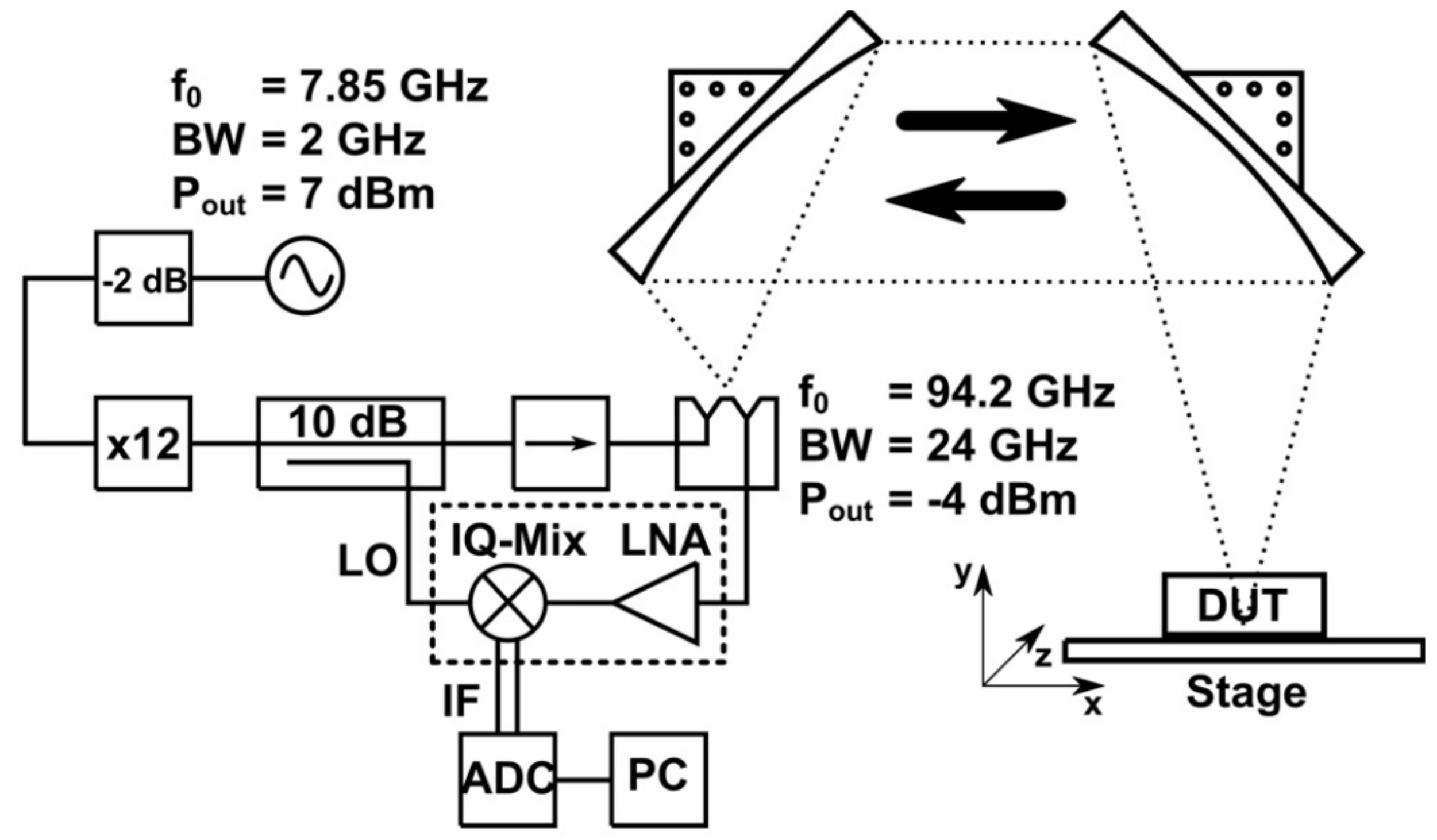




\section{Control \&}

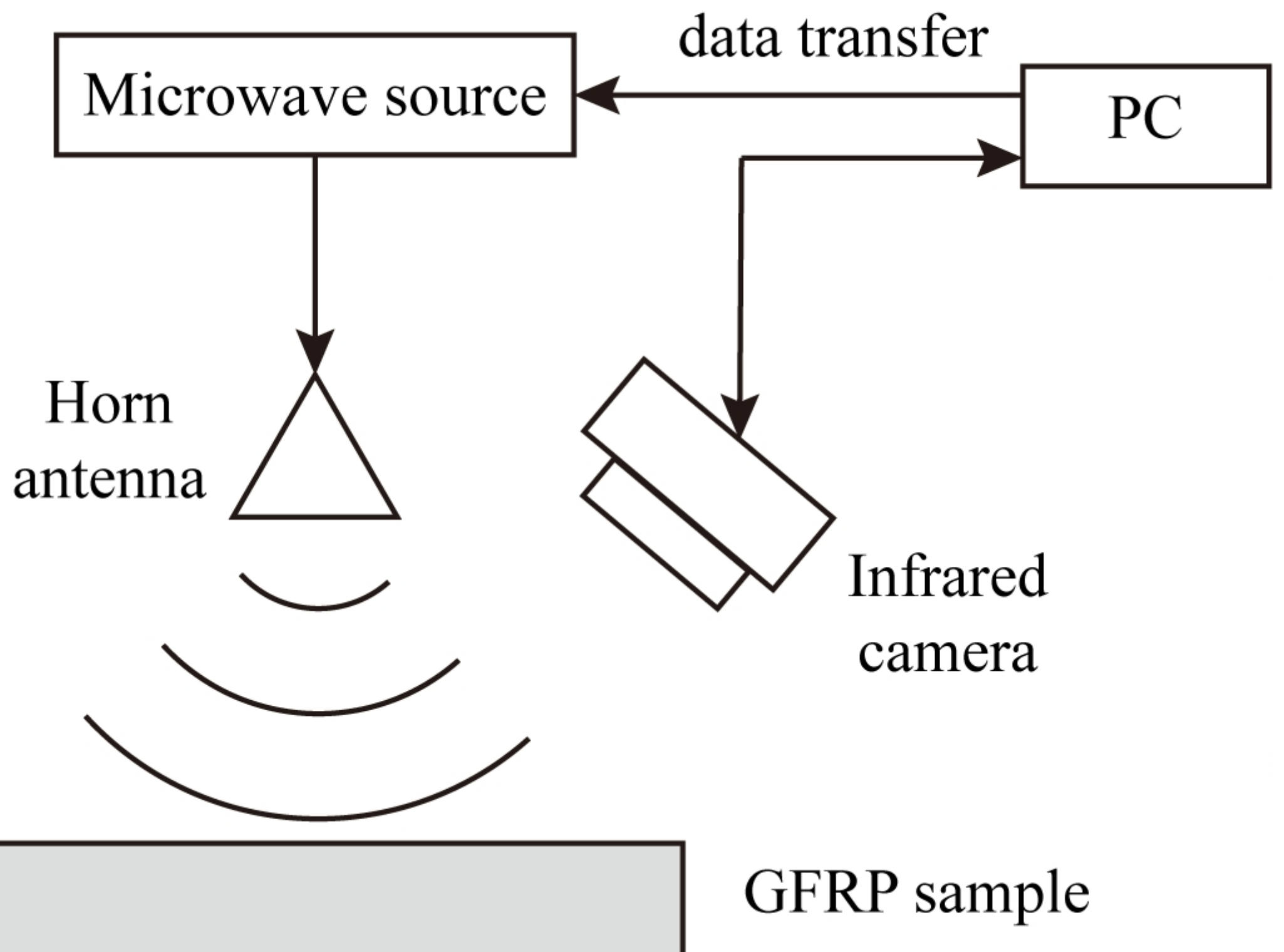

